\title{
Anatomic Organization of the Basilar Pontine Projections from Prefrontal Cortices in Rhesus Monkey
}

\author{
Jeremy D. Schmahmann ${ }^{1}$ and Deepak N. Pandya ${ }^{2}$ \\ ${ }^{1}$ Department of Neurology, Massachusetts General Hospital and Harvard Medical School, Boston, Massachusetts \\ 02114, and 2Harvard Neurological Unit, Beth Israel Hospital, Boston, Massachusetts 02114, and Department of Anatomy \\ and Neurobiology, Boston University School of Medicine, Boston, Massachusetts 02114
}

In our ongoing attempt to determine the anatomic substrates that could support a cerebellar contribution to cognitive processing, we investigated the prefrontal cortical projections to the basilar pons. A detailed understanding of these pathways is needed, because the prefrontal cortex is critical for a number of complex cognitive operations, and the corticopontine projection is the obligatory first step in the corticopontocerebellar circuit. Prefrontopontine connections were studied using the autoradiographic technique in rhesus monkey. The pontine projections were most prominent and occupied the greatest rostrocaudal extent of the pons when derived from the dorsolateral prefrontal convexity, including areas 8Ad, 9/46d, and 10. Lesser pontine projections were observed from the medial prefrontal convexity and area $45 \mathrm{~B}$ in the inferior limb of the arcuate sulcus. In contrast, ventral prefrontal and orbitofrontal cortices did not demonstrate pontine projections. The prefrontopontine terminations were located preferentially in the paramedian nucleus and in the medial parts of the peripeduncular nucleus, but each cortical area appeared to have a unique complement of pontine nuclei with which it is connected. The existence of these corticopontine pathways from prefrontal areas concerned with multiple domains of higher-order processing is consistent with the hypothesis that the cerebellum is an essential node in the distributed corticosubcortical neural circuits subserving cognitive operations.

Key words: frontal lobe; pons; cerebellum; connections; anatomy; behavior; cognition
The corticopontine projection is the obligatory first step in the feedforward limb of the cerebrocerebellar circuit. Several investigators have described pontine projections from cerebral association areas (Nyby and Jansen, 1951; Brodal, 1978; Wiesendanger et al., 1979; Glickstein et al., 1985; May and Andersen, 1986; Fries, 1990). Our recent investigations have revealed that there are projections to the pons from unimodal as well as multimodal association areas in the posterior parietal, superior temporal, and occipitotemporal cortices as well as from the parahippocampal gyrus (Schmahmann and Pandya, 1989, 1991, 1993). Vilensky and Van Hoesen (1981) have demonstrated pontine connections from the limbic system arising in the cingulate gyrus.

Recent functional neuroimaging data in human subjects (Petersen et al., 1989; Dolan et al., 1992; Ryding et al., 1993; Jenkins et al., 1994; Kim et al., 1994; Parsons et al., 1995) and clinical evidence derived from patients with cerebellar lesions (Bauman and Kemper, 1994; Silveri et al., 1994; Sherman and Schmahmann, 1995) have provided supportive evidence for earlier physiological (Reis et al., 1973; Cooper et al., 1974) and behavioral investigations (Berman et al., 1978), suggesting a role for the cerebellum in cognitive operations and affective processes (Dow and Moruzzi, 1958; Dow, 1974; Snider and Maiti, 1976; Heath, 1977; Watson, 1978; Schmahmann, 1991,

Received July 12, 1996; revised Oct. 10, 1996; accepted Oct. 16, 1996.

This work was supported in part by the Veterans Administration, Edith Nourse Rogers Memorial Veterans Hospital (Bedford, MA), National Institutes of Health Grant 16841, and the Milton Fund of Harvard University. We thank Mr. Andrew Doolittle and Ms. Amy Hurwitz for technical assistance, and we thank Ms. Marygrace Neal for secretarial assistance.

Correspondence should addressed to Dr. Jeremy D. Schmahmann, Department of Neurology, Burnham 823, Massachusetts General Hospital, Fruit Street, Boston, MA 02114.

Copyright (C) 1996 Society for Neuroscience $0270-6474 / 96 / 160438-21 \$ 05.00 / 0$
1996). Cerebellar patients have difficulties with executive function (Grafman et al., 1992) and verbal fluency (Fiez et al., 1992), problems generally seen in the setting of frontal lobe dysfunction (Fuster, 1980). This has been interpreted as representing a disruption of cerebellar modulation of functions subserved by the frontal lobe. Implicit in this hypothesis is that the cerebellum is part of a distributed neural system (Mesulam, 1981; Goldman-Rakic, 1988; Posner et al., 1988) that incorporates the higher-order areas including the prefrontal cortices (Leiner et al., 1986, 1993; Schmahmann and Pandya, 1987, 1989, 1991, 1993; Botez et al., 1989; Schmahmann, 1991, 1996; Grafman et al., 1992; Ito, 1993; Middleton and Strick, 1994).

There is evidence from earlier indirect observations (Kievit and Kuypers, 1977; Sasaki et al., 1979; Stanton, 1980) and from more recent direct transsynaptic experiments (Middleton and Strick, 1994) that the cerebellar dentate nucleus has a feedback projection to the prefrontal cortex (PFC). There is a paucity, however, of anatomic evidence demonstrating a feedforward contribution to the cerebellum from prefrontal cortices concerned with complex cognitive operations. There is a substantial body of literature that has evolved since the last century that deals with the frontopontine projection in the nonhuman primate. The principal findings of these earlier investigations are summarized in Table 1. For the most part, however, this work has not focused on the PFC specifically and, consequently, a number of essential details are still unavailable.

Our interest in the pontine projections from the PFC is part of a larger investigation of the input to the feedforward limb of the cerebrocerebellar system from nonmotor cerebral regions concerned with higher-order behavior. Using the same techniques and methodology as in our previous investigations, we conducted a systematic study in the rhesus monkey of the prefrontopontine 
Table 1. Summary of previous principal findings

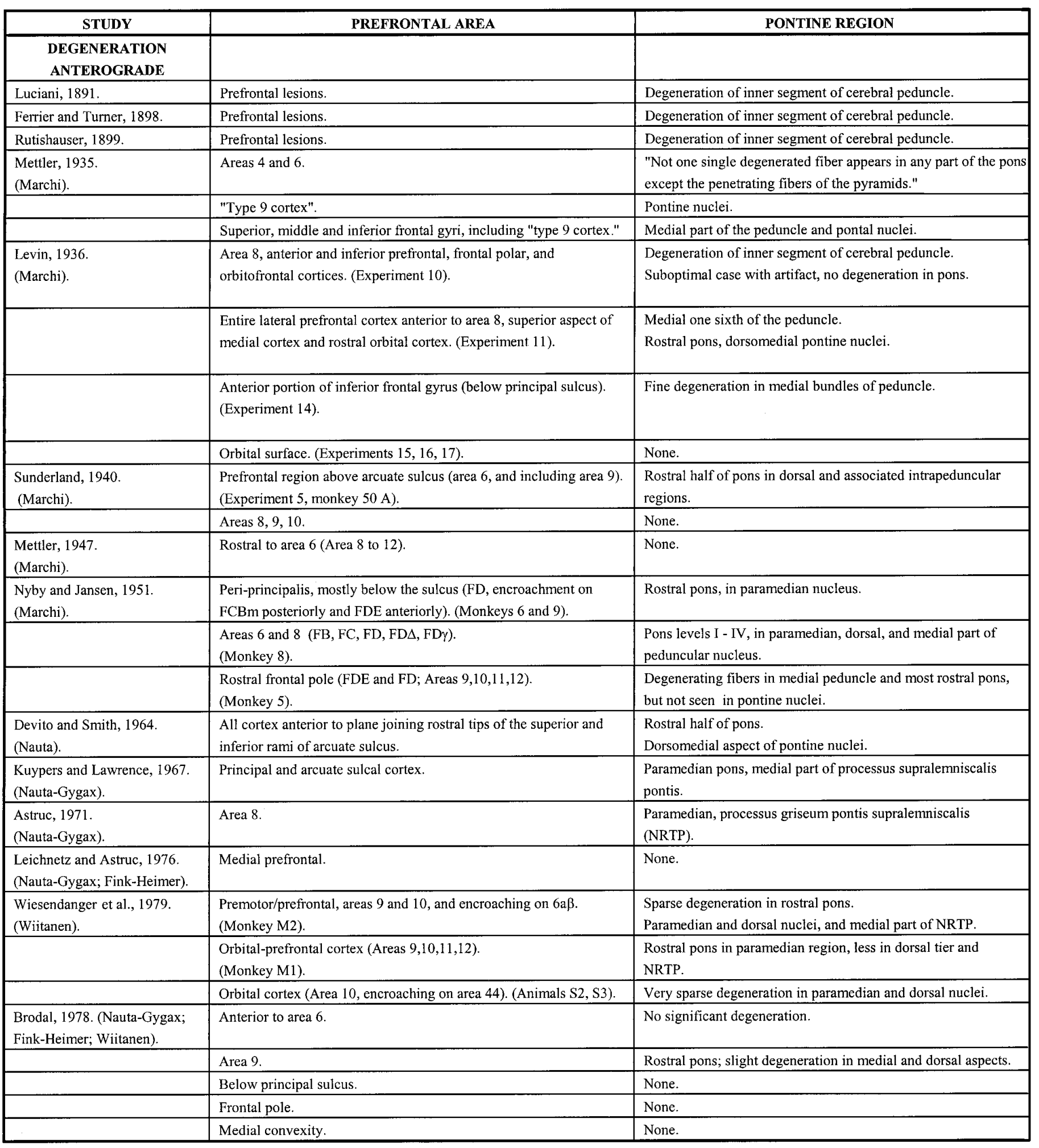

Table 1 continues.

pathways. We sought to determine the precise origins of the pontine projections within the PFC, as well as the detailed pattern of terminations within the nuclei of the basilar pons. The PFC is segregated into functionally distinct regions that are matched by a connectional heterogeneity, such that each of the prefrontal subdivisions has a different set of connections with cortical as well as subcortical structures (Pandya and Yeterian, 1991). We wished to determine whether the differential organization of the prefrontopontine projection reflects this cortical anatomic and functional heterogeneity. Preliminary results of these investigations have been presented elsewhere, but the precise arrangement within the basilar pons of the prefrontopontine terminations have not been 
Table 1. Summary of previous principal findings

\begin{tabular}{|l|l|l|}
\hline \multicolumn{1}{|c|}{ STUDY } & \multicolumn{1}{|c|}{ PREFRONTAL AREA } & \multicolumn{1}{|c|}{ PONTINE REGION } \\
ISOTOPE & & \\
\hline Künzle and Akert, 1977. & Area 8. & $\begin{array}{l}\text { Rostral half of pons, moderate to dense projections; in } \\
\text { dorsolateral, dorsomedial, intermediate, and ventral regions, } \\
\text { and paramedian NRTP bilaterally. }\end{array}$ \\
\hline Wiesendanger et al, 1979. & Area 9. & Rostral pons; in paramedian, dorsal, and ventral regions. \\
\hline $\begin{array}{l}\text { Hartmann-von Monakow et } \\
\text { al., 1981. }\end{array}$ & Area 8. & $\begin{array}{l}\text { Rostral two-thirds of pons in dorsal and lateral regions and } \\
\text { dorsomedial NRTP. }\end{array}$ \\
\hline & Area 9. & $\begin{array}{l}\text { Weak label in rostral pons, in dorsal region and medioventral } \\
\text { NRTP. }\end{array}$ \\
\hline $\begin{array}{l}\text { Vilensky and Van Hoesen, } \\
1981 .\end{array}$ & Area 10. & Uncertain (none, short survival times). \\
\hline Stanton et al., 1988. & Area 8. & Dorsomedial, medial, ventromedial pons. \\
\hline \begin{tabular}{l} 
Shook et al., 1990. \\
\hline
\end{tabular} & Supplementary eye fields, frontal eye fields. & $\begin{array}{l}\text { Dorsomedial, paramedian, medial peripeduncular and } \\
\text { dorsolateral regions, and NRTP. }\end{array}$ \\
\hline
\end{tabular}

\begin{tabular}{|l|l|l|}
\hline \multicolumn{1}{|c|}{$\begin{array}{c}\text { WGA-HRP } \\
\text { ANTEROGRADE }\end{array}$} & & \\
\hline Leichnetz et al., 1984. & $\begin{array}{l}\text { Area 8. } \\
\text { (Cases MF 67,19). }\end{array}$ & $\begin{array}{l}\text { Dorsomedial and small projection to dorsolateral pons, } \\
\text { dorsomedial NRTP. }\end{array}$ \\
\hline
\end{tabular}

\begin{tabular}{|l|l|l|}
\hline \multicolumn{1}{|c|}{$\begin{array}{c}\text { WGA-HRP } \\
\text { RETROGRADE }\end{array}$} & \\
\hline Leichnetz et al., 1984. & $\begin{array}{l}\text { Densest neuronal labeling in periarcuate cortex (areas 6 and 8), and } \\
\text { to lesser extent in entire lateral and dorsomedial prefrontal cortex. }\end{array}$ & $\begin{array}{l}\text { Injection in dorsomedial pontine gray, ventromedial NRTP, } \\
\text { and caudal interpeduncular nucleus. } \\
\text { Cases CB 60, 61. }\end{array}$ \\
\hline Glickstein et al., 1985. & $\begin{array}{l}\text { Area 8, Area 9 (cortex above principal sulcus, seems to include area } \\
\text { 46d). Labeled neurons in cortex. }\end{array}$ & Injection in entire pons. \\
\hline & $\begin{array}{l}\text { Area 9 (cortex below principal sulcus, including area 46v), areas 10 } \\
\text { and 11. No labeled neurons in cortex. }\end{array}$ & Injection in entire pons. \\
\hline & Cingulate cortex (areas 24, 25). Modest amount of labeled neurons. & Injection in entire pons. \\
\hline
\end{tabular}

\section{Table 1 continued.}

previously published. The pons is the intermediate step in the feedforward limb of the cerebrocerebellar circuit and, therefore, this detailed topographic map is essential for determining the anatomic relationship between nonmotor areas of the cerebral hemispheres and the cerebellum. Furthermore, we were interested in establishing how the projections from the prefrontal association cortices differ from those derived from the posteriorly situated association areas. Therefore, in the present report, we have investigated the corticopontine projections from functionally and architectonically distinct prefrontal areas using the anterograde tracer technique.

Preliminary results of our investigations have been presented previously. (Schmahmann and Pandya, 1995).

\section{MATERIALS AND METHODS}

In 18 adult rhesus monkeys, the prefrontopontine projections were studied using radiolabeled anterograde tracers. Two closely adjacent injections of $0.5 \mu \mathrm{l}$ of tritiated leucine and proline (volume range, $0.4-1.2 \mu \mathrm{l}$, specific activity range, $40-80 \mu \mathrm{Cu}$, aqueous solution) were made in each case. Animals were anesthetized with ketamine hydrochloride $(10 \mathrm{mg} / \mathrm{kg})$ and sodium pentobarbital $(30 \mathrm{mg} / \mathrm{kg}$ ), and the cerebral cortex was exposed by craniotomy and reflection of the dura. Regions of the PFC defined previously by cytoarchitectonic criteria (Petrides and Pandya,
1994) (Fig. 1D) were identified by inspection of the sulcal pattern, and injections were made under direct visual guidance with a $1 \mu$ l Hamilton syringe and a microdrive attachment. Cortical injections were made at a depth of $2 \mathrm{~mm}$, and sulcal injections were made at a depth of 4-6 mm. After a survival period of $7 \mathrm{~d}$, the animals were killed under deep Nembutal anesthesia by transcardial perfusion of saline. The animals were then perfused with $10 \%$ formalin and the brains removed. The brainstem was separated from the cerebral hemispheres rostral to the level of the inferior colliculus at $90^{\circ}$ to the long axis of the pons. The brainstem and cerebellum were embedded in paraffin and cut in transverse section at a thickness of $10 \mu \mathrm{m}$ and mounted on glass slides. The slides were immersed in Kodak NTB-2 nuclear track emulsion, exposed for 4-6 months, developed in Kodak D-19, fixed in Kodak Rapid-Fix, then counterstained with thionin, and coverslipped (Cowan et al., 1972). Transverse sections through the rostrocaudal extent of the pons were drawn with the aid of a magnifier, the distribution of terminal label studied with dark-field microscopy, and axon termination fields were plotted on these drawings using a side-arm viewer. Nine levels of the pons at approximately equal intervals were selected in each case to depict the findings. These levels, I to IX from rostral to caudal pons, and the cytoarchitectonic characteristics and boundaries of the pontine nuclei correspond to those described by Nyby and Jansen (1951) and Schmahmann and Pandya $(1989,1991)$ (Fig. 2). The nomenclature used for describing the location of the PFC injection sites in this study follows the architectonic parcellation of Petrides and Pandya (1994) (Fig. 1D). Many of the cases used in this study have been analyzed in other investigations 

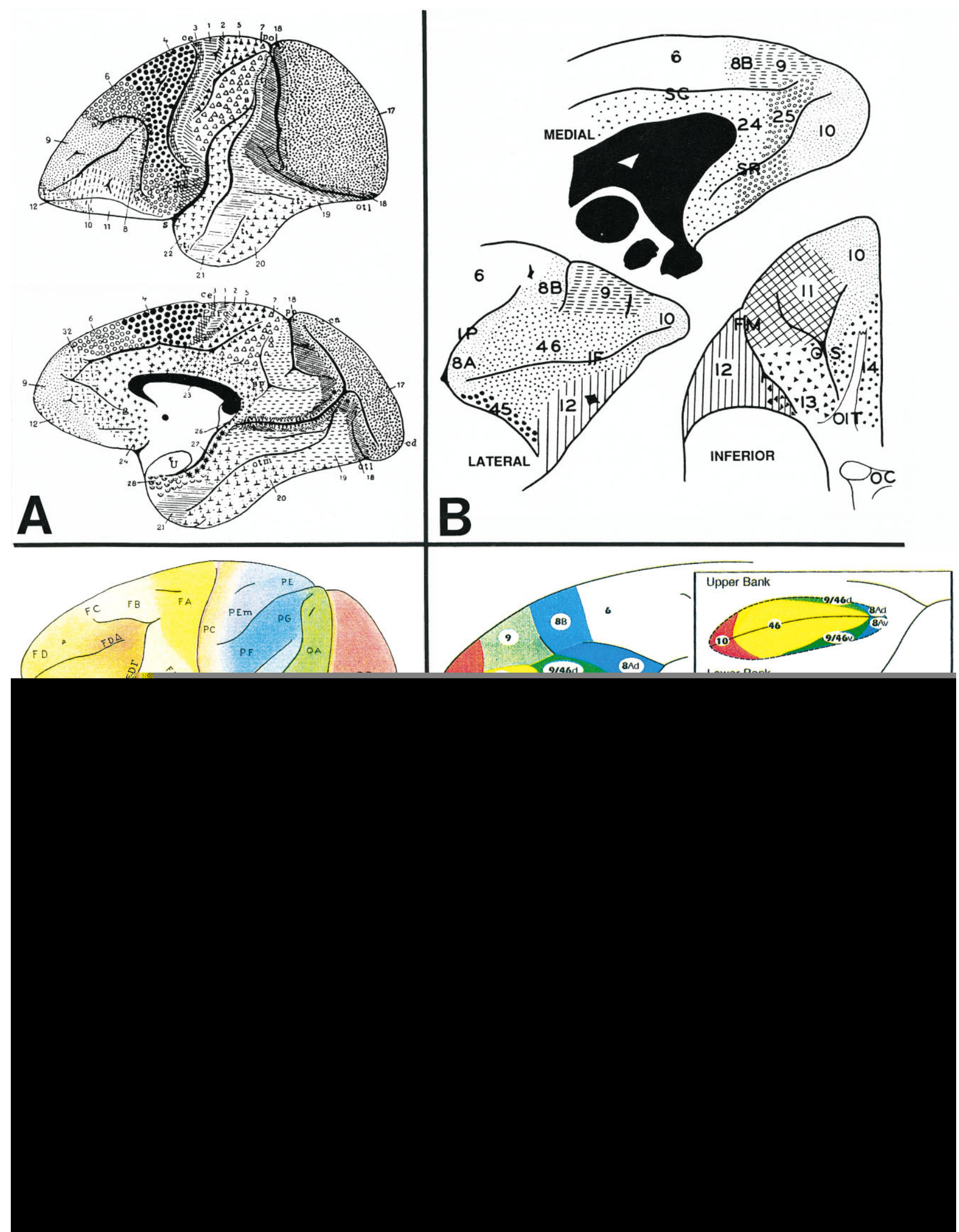

Figure 1. Diagrams of the cerebral hemispheres of rhesus monkey illustrating the architectonic areas of the prefrontal cortices according to the designations of Brodmann (1909) $(A)$, Walker (1940) $(B)$, von Bonin and Bailey (1947) $(C)$, and Petrides and Pandya (1994) $(D)$. This figure illustrates the extent of the PFC, and the earlier nomenclature is presented to assist in the interpretation of the results of the studies that are cited in Table 1. 

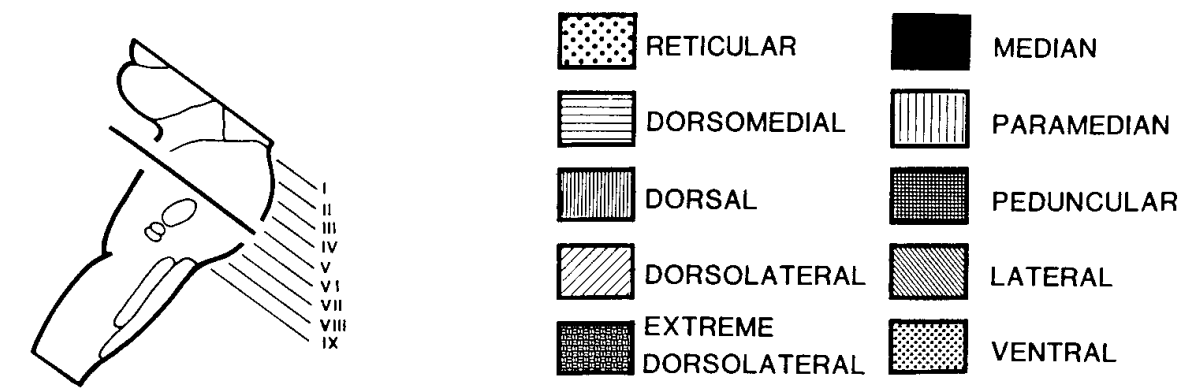

I

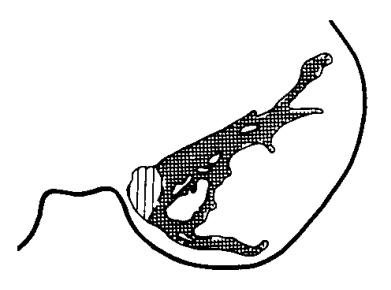

॥

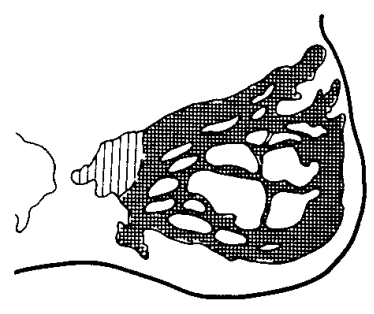

III

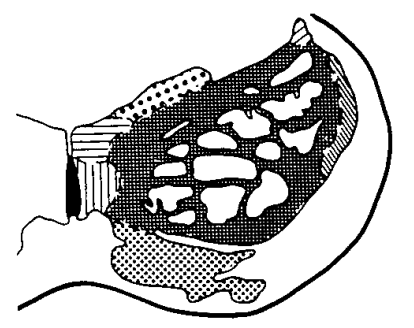

IV

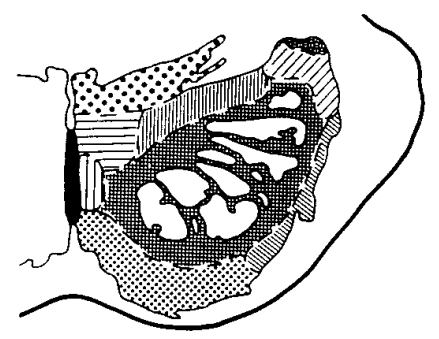

V

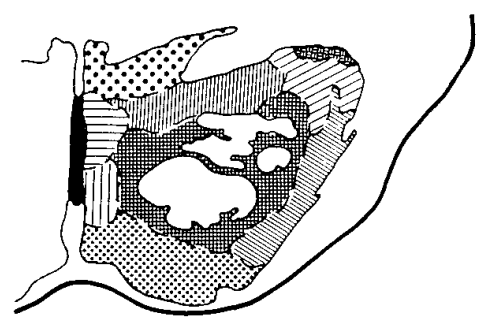

VI

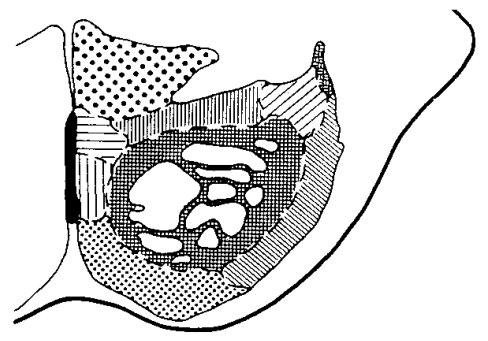

VII

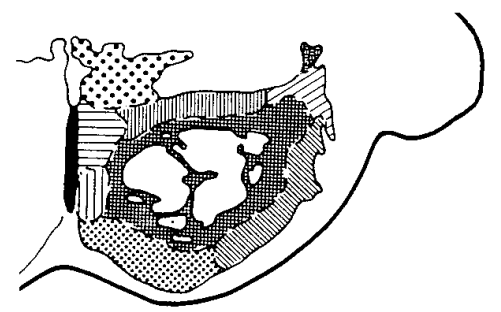

Figure 2. Diagram showing the subdivisions of the pontine nuclei in the transverse plane (perpendicular to the long axis of the pons) according to Nyby and Jansen (1951), with modifications according to our observations (Schmahmann and Pandya, 1989, 1991). I-IX represent the rostrocaudal levels at equal intervals through the pons.

of cortical and subcortical projections of the prefrontal region (Barbas and Pandya, 1989; Yeterian and Pandya, 1991).

\section{RESULTS}

\section{Injections that resulted in pontine terminations}

Medial prefrontal cases

The isotope injections in cases 1 and 2 (Figs. 3C,D, 4) were placed in the medial PFC and involved area 32. The resulting label was present in the rostral third of the ipsilateral pons and was distributed primarily in the medial portion of the peduncular and peripeduncular nuclei and in the paramedian nucleus.

In case 3 , the injection was placed above the cingulate sulcus in the rostral part of the superior frontal gyrus and involved the rostral and medial part of area 9 (Fig. 5). The terminal label was distributed in the rostral two-thirds of the ipsilateral pons. This was the only case in the series in which label was observed in the 


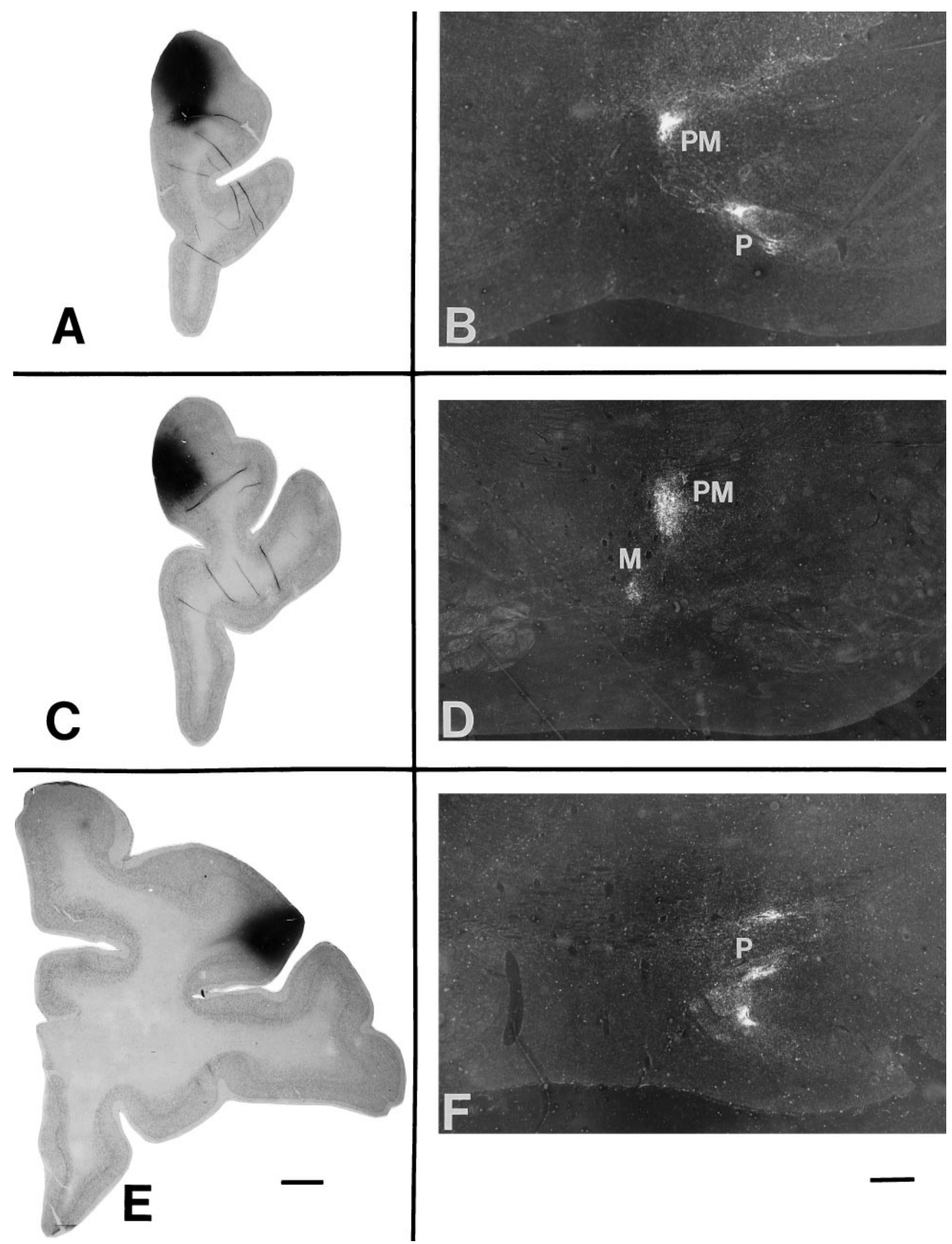

Figure 3. Light-field photographs of coronal sections through isotope injections in three representative cases (left), and dark-field photomicrographs of the resulting anterogradely transported terminal label in the nuclei of the ipsilateral basis pontis $($ right $)$. $A$, Area 10 injection in case 5 , with terminal label seen in $B$ in level III of the pons in the paramedian $(P M)$ and peripeduncular $(P)$ nuclei. $C$, Isotope injection in case 2 in area 9 at the medial convexity, with terminal label seen in $D$ in level II of the pons in the median $(M)$ and paramedian nuclei. $E$, Injection site in case 9 , in area $9 / 46$ d, with terminal label in level II of the pons $(F)$ in the paramedian nucleus. Injection sites $(A, C, E)$ : scale bar (shown in $E), 20 \mathrm{~mm}$; pontine terminations $(B, D, F)$ : scale bar (shown in $F$ ), $2 \mathrm{~mm}$ 


\section{CASE 1}

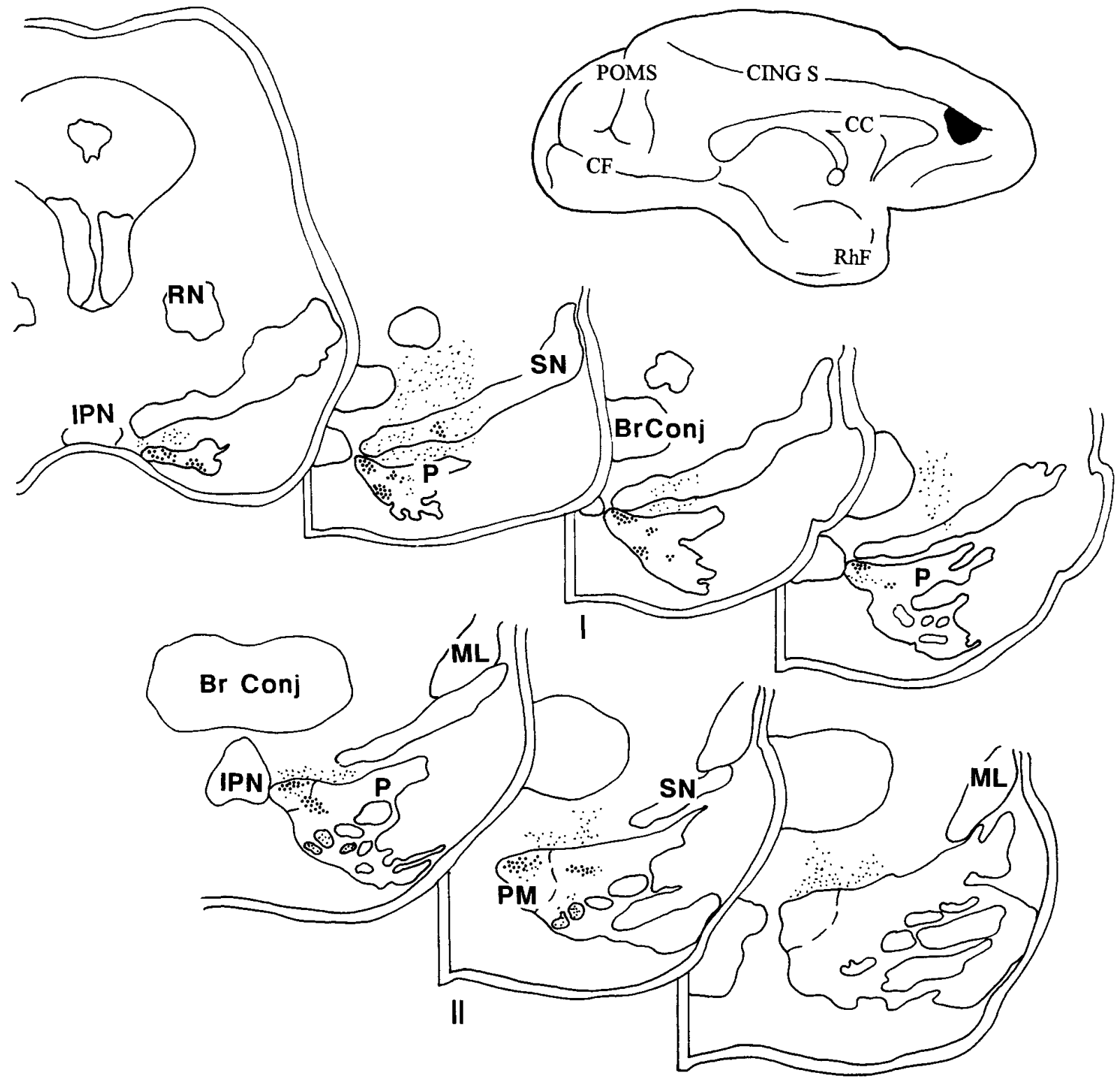

Figure 4. Diagram illustrating the medial surface of the cerebral hemisphere of case 1, in which the isotope injection (shown in black) was placed in the medial PFC and involved area 32. The resulting fibers (small black dots) were present in the rostral third of the ipsilateral pons. The terminal label (large black dots) was distributed primarily in the medial portion of the peduncular and peripeduncular nuclei and in the paramedian nucleus. Abbreviations for cerebral hemispheres (Figs. 4-17): $A S$, arcuate sulcus; $C I N G S$, cingulate sulcus; $C C$, corpus callosum; $C F$, calcarine fissure; $C S$, central sulcus; $I O S$, inferior occipital sulcus; IPS, intraparietal sulcus; $L F$, lateral (Sylvian) fissure; $L S$, lunate sulcus; Orb $S$, orbital sulcus; OTS, occipitotemporal sulcus; $P O M S$, parieto-occipital medial sulcus; $P S$, principalis sulcus; $R h F$, rhinal fissure; $S T S$, superior temporal sulcus. Abbreviations for brainstem sections (Figs. 4-17): $B r$ Conj, brachium conjunctivum; $D$, dorsal pontine nucleus; $D L$, dorsolateral pontine nucleus; $D M$, dorsomedial pontine nucleus; $E D L$, extreme dorsolateral pontine nucleus; $I P N$, interpeduncular nucleus; $L$, lateral pontine nucleus; $M$, median pontine nucleus; $M L$, medial lemniscus; $N R T P$, nucleus reticularis tegmenti pontis; $P$, peduncular nucleus (peripeduncular vs intrapeduncular not differentiated in the diagrams); $P M$, paramedian pontine nucleus; $R$, nucleus reticularis tegmenti pontis; $R N$, red nucleus; $S N$, substantia nigra; $V$, ventral pontine nucleus.

median nucleus. Additionally, grains were detected in the paramedian nucleus, as well as in the nucleus reticularis tegmenti pontis (NRTP). The contralateral NRTP also had a small projection located between pontine levels IV and V.

In case 4 , the injection was placed in the medial surface of the hemisphere above the cingulate sulcus at a level corresponding to the rostral tip of the corpus callosum and involved area $8 \mathrm{~B}$ (Fig.
6). Terminations were noted in the rostral half of the ipsilateral pons in the paramedian nucleus, the medial part of the peripeduncular nucleus, and the NRTP.

In case 5, the injection was placed in the rostral part of the PFC and involved the medial and dorsal sectors of area 10 (Figs. $3 A, B$, $7)$. The terminal label in this case was observed throughout the rostro-caudal extent of the ipsilateral pons and involved the para- 


\section{CASE 3}

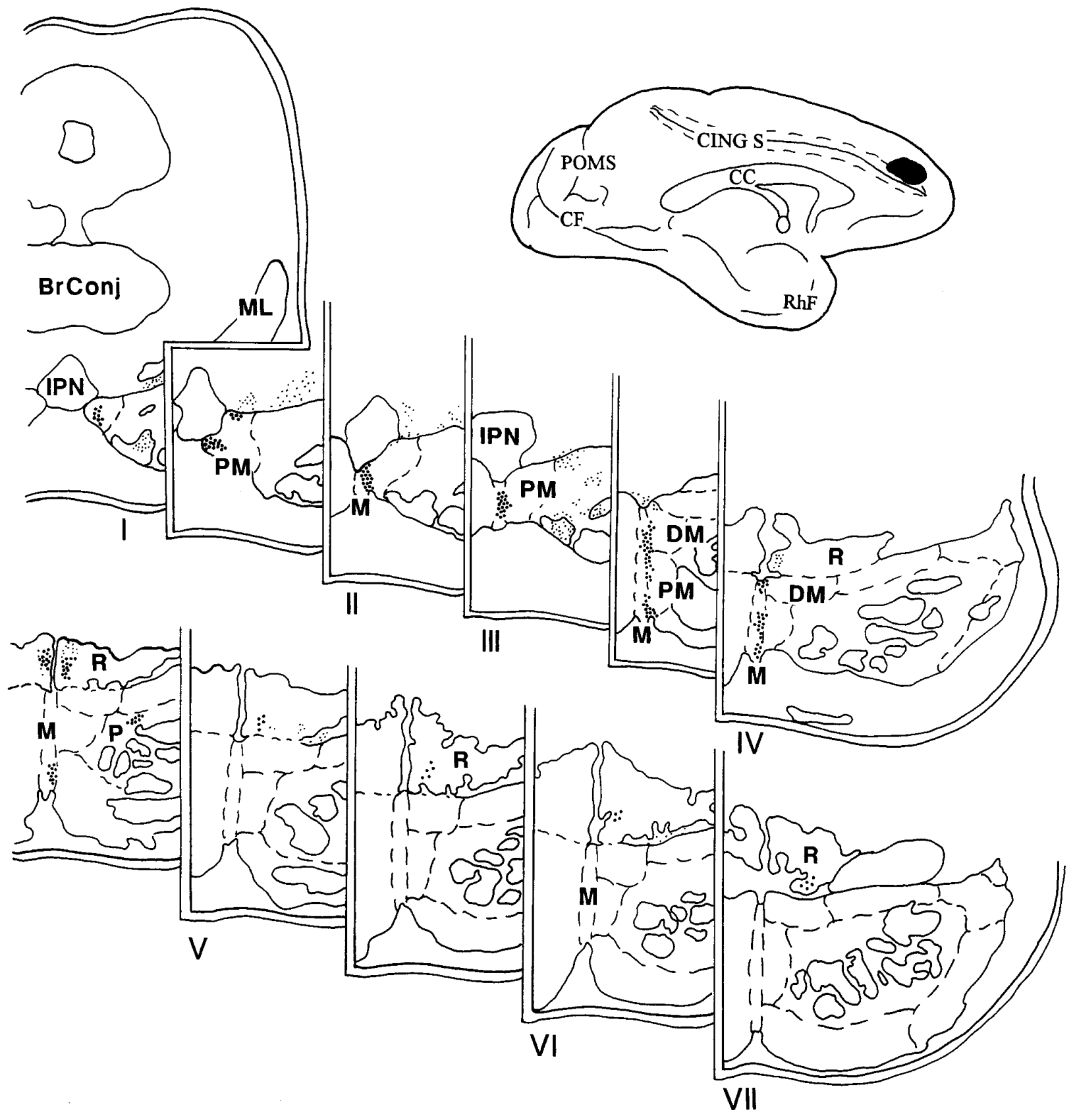

Figure 5. Diagram illustrating the medial surface of the cerebral hemisphere of case 3, in which the isotope was placed above the cingulate sulcus in the rostral part of the superior frontal gyrus and involved the rostral and medial part of area 9. Terminal label was distributed in the rostral two-thirds of the ipsilateral pons and was present in the median nucleus, the paramedian and dorsomedial nuclei, and the NRTP. The contralateral NRTP also had a small projection in between pontine levels IV and V.

median, peripeduncular, and dorsomedial nuclei and the NRTP. Caudally, some label was also noted in the ventral and lateral pontine nuclei as well.

\section{Dorsolateral prefrontal cases}

The injection in cases 6 (Fig. 8) and 7 (data not shown) were placed in the PFC above the midportion of the principal sulcus and involved lateral area 9. The resulting label was essentially identical in both cases and was noted throughout the rostrocaudal extent of the ipsilateral pons occupying a thin dorsal-ventral lamella adjacent to the midline. The lamella spanned the paramedian nucleus and the medial part of the peripeduncular nucleus, as well as the dorsomedial and ventral nuclei and the NRTP.

In case 8 , the injection was placed in the rostral part of the dorsolateral PFC and included the rostral part of area 9 and dorsal area 10 (Fig. 9). Label was restricted to the rostral half of the ipsilateral pons and was located primarily in the paramedian and peripeduncular nuclei. Some label was also noted in the NRTP. 


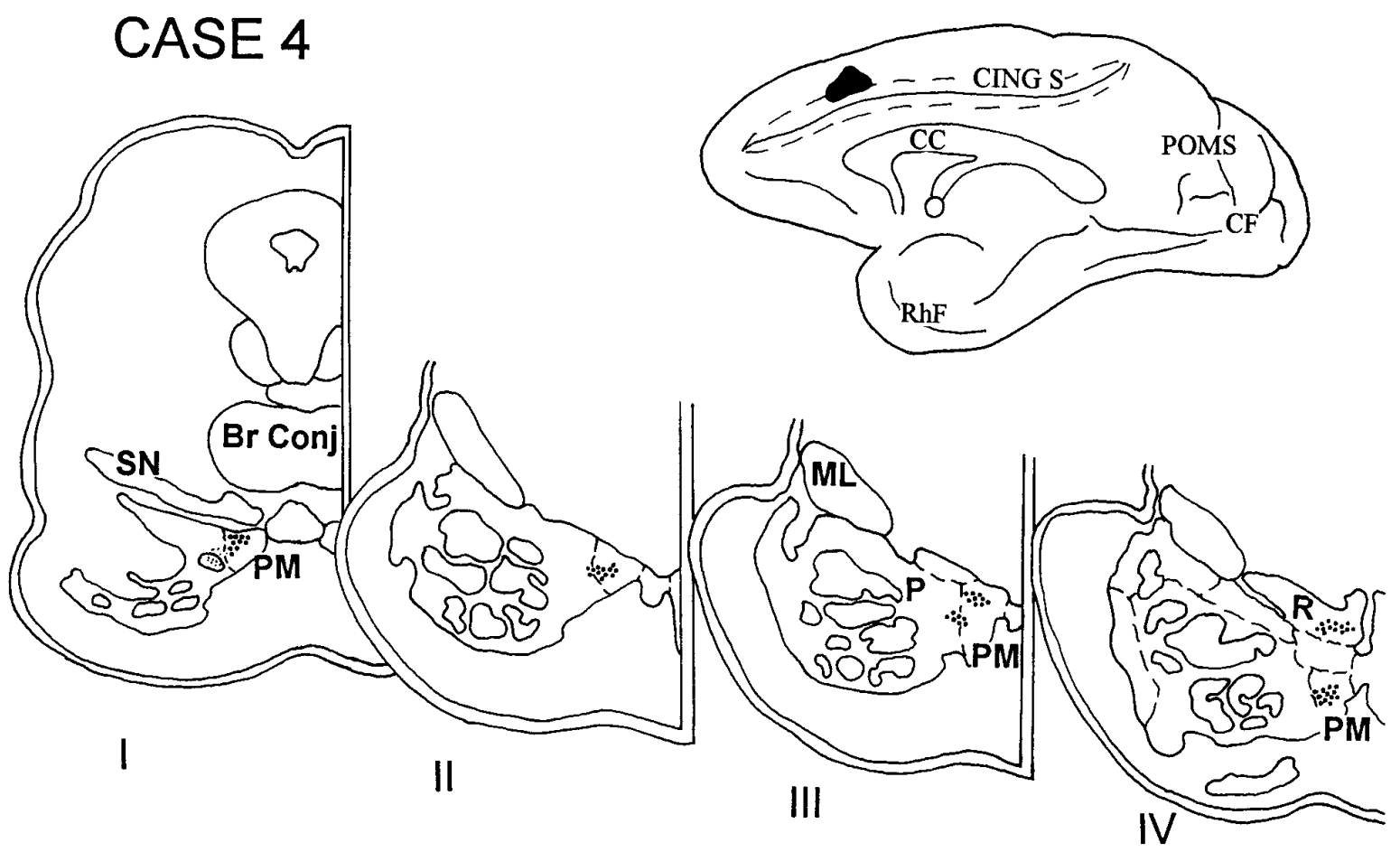

Figure 6. Diagram illustrating the medial surface of the cerebral hemisphere of case 4, in which isotope was injected in the medial surface of the hemisphere above the cingulate sulcus at a level corresponding to the rostral tip of the corpus callosum and involved area 8B. The terminal label was distributed in the rostral half of the ipsilateral pons and in the paramedian nucleus, the medial part of the peripeduncular nucleus, and the NRTP.

The injection in case 9 was placed in the caudal part of the upper bank of the principal sulcus and the adjacent gyral cortex and involved area 9/46d (Figs. 3E,F,10). The label was distributed throughout the rostrocaudal extent of the ipsilateral pons and was observed somewhat more laterally when compared with previous cases. Label was seen predominantly in the peripeduncular, paramedian, and dorsomedial nuclei, as well as in the NRTP and the medial part of the ventral nucleus.

In case 10 , the isotope injection was placed in the cortex lying in the rostral bank of the upper limb of the arcuate sulcus and adjacent gyral cortex and involved area 8Ad (Fig. 11). The resulting label was distributed throughout the rostrocaudal extent of the ipsilateral pons. Terminations were present primarily in the paramedian and dorsomedial nuclei and in the medial and ventral parts of the peripeduncular nucleus. Additionally, in the caudal pons, grains were noted in the ventral and lateral nuclei, and some were also observed in the NRTP.

The injection in case 11 was placed within the caudal part of the ventral bank of the principal sulcus and the adjacent gyral cortex and involved area 9/46v (Fig. 12). Terminal label occupied the rostral half of the ipsilateral pons and was detected primarily in the paramedian nucleus, with some label seen in the dorsomedial nucleus and in the medial part of the peripeduncular nucleus.

In cases 12 and 13, the isotope injections were placed in the cortex lying in the rostral bank of the lower limb of the arcuate sulcus and involved area 45B. The injection in case 12 (Fig. 13) was slightly dorsal to that in case 13 (Fig. 14). The label in both these cases was restricted to the rostral third of the ipsilateral pons and was localized in the paramedian nucleus and in the medial and ventral parts of the peripeduncular nucleus.

\section{Injections that did not result in pontine terminations} Orbitofrontal and adjacent ventral lateral prefrontal cases

In the next four cases (Fig. 15), the isotope injection involved area 46 below the principal sulcus (case 14); the caudal part of the orbital cortex, area 47/12 (case 15); the midlateral portion of the orbital cortex, area 47/12 (case 16); the rostral part of the orbital cortex, area 11 (case 17); and the ventral region of the medial PFC, area 14 (case 18). In each case, labeled fibers were seen to leave the injection site and travel toward different cortical destinations within the same and opposite hemispheres. Some subcortically directed fibers entered the anterior limb of the internal capsule and terminated in the thalamus. None of these cases, however, demonstrated labeled fibers conforming to the expected trajectory of the prefrontopontine fiber system (Schmahmann and Pandya, 1994), traversing the anterior limb of the internal capsule and descending into the cerebral peduncle. None of these cases resulted in the distribution of terminal label in the pontine nuclei.

\section{Summary of anatomic results}

The results of our investigations confirm many of the earlier reports and extend these observations by defining both the origins and the differential terminations of the prefrontopontine projection. Cortical areas that contribute most heavily to the pons include area 9/46d located above the principal sulcus, area 8Ad in the arcuate concavity, area 9 at the dorsolateral convexity, and area 10 at the rostral parts of the dorsolateral and medial convexities. Area $8 \mathrm{~B}$ and area 32 at the medial surface of the hemisphere, area 9 at the medial convexity, and area 9/46v contribute a distinct but somewhat less intense pontine projection. A minor pontine projection also arises from area $45 \mathrm{~B}$ in the rostral bank of the inferior limb of the arcuate sulcus. Pontine projections are not 


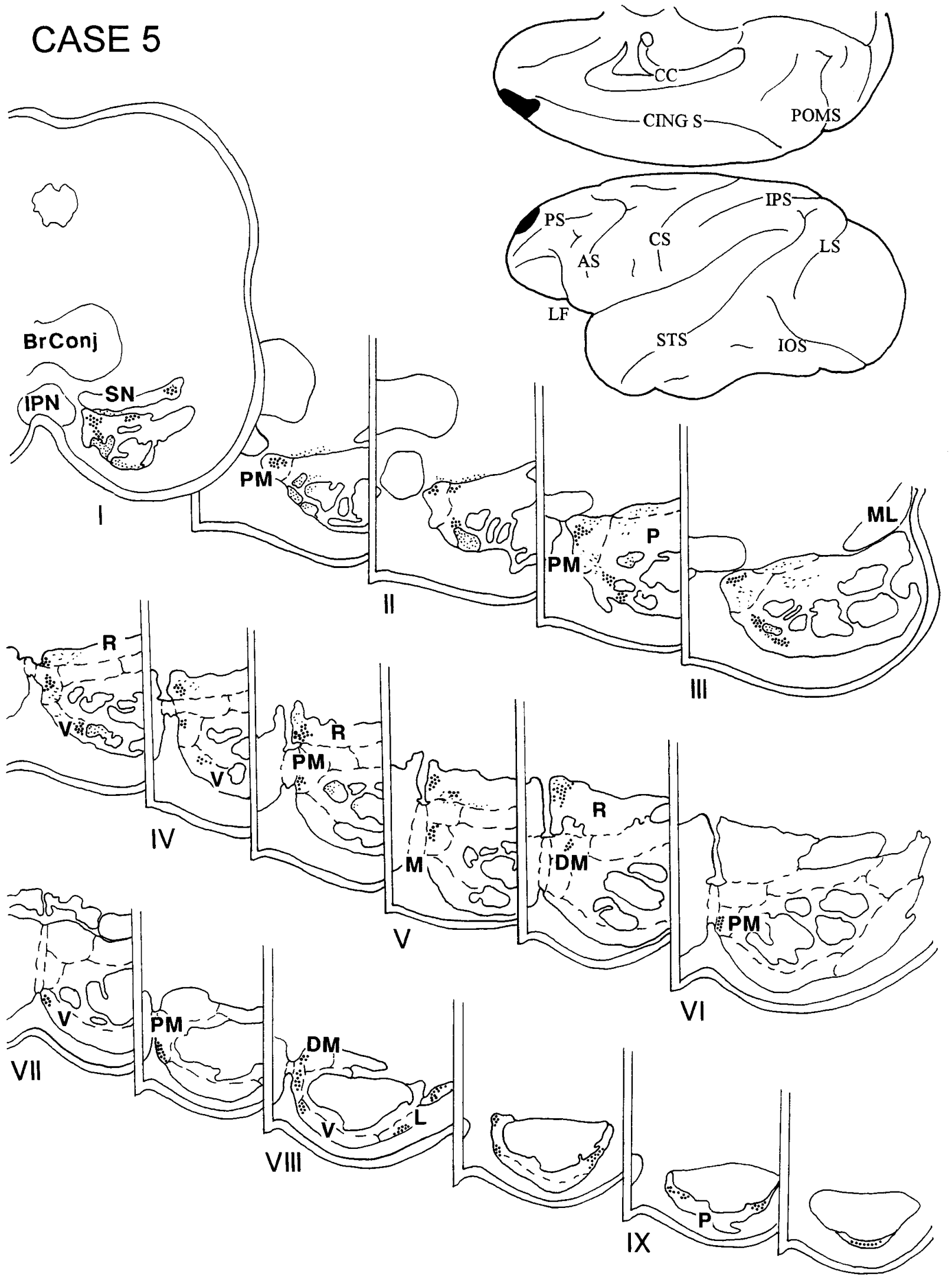

Figure 7. Diagram illustrating the medial and lateral surfaces of the cerebral hemisphere of case 5, in which the isotope was placed in the rostral part of the PFC and involved the medial and dorsal sectors of area 10. Terminal label was observed in levels I-IX of the ipsilateral pons and involved the paramedian, peripeduncular, and dorsomedial nuclei and the NRTP. A small amount of label was noted in the ventral and lateral nuclei at caudal levels of the pons. 
CASE 6

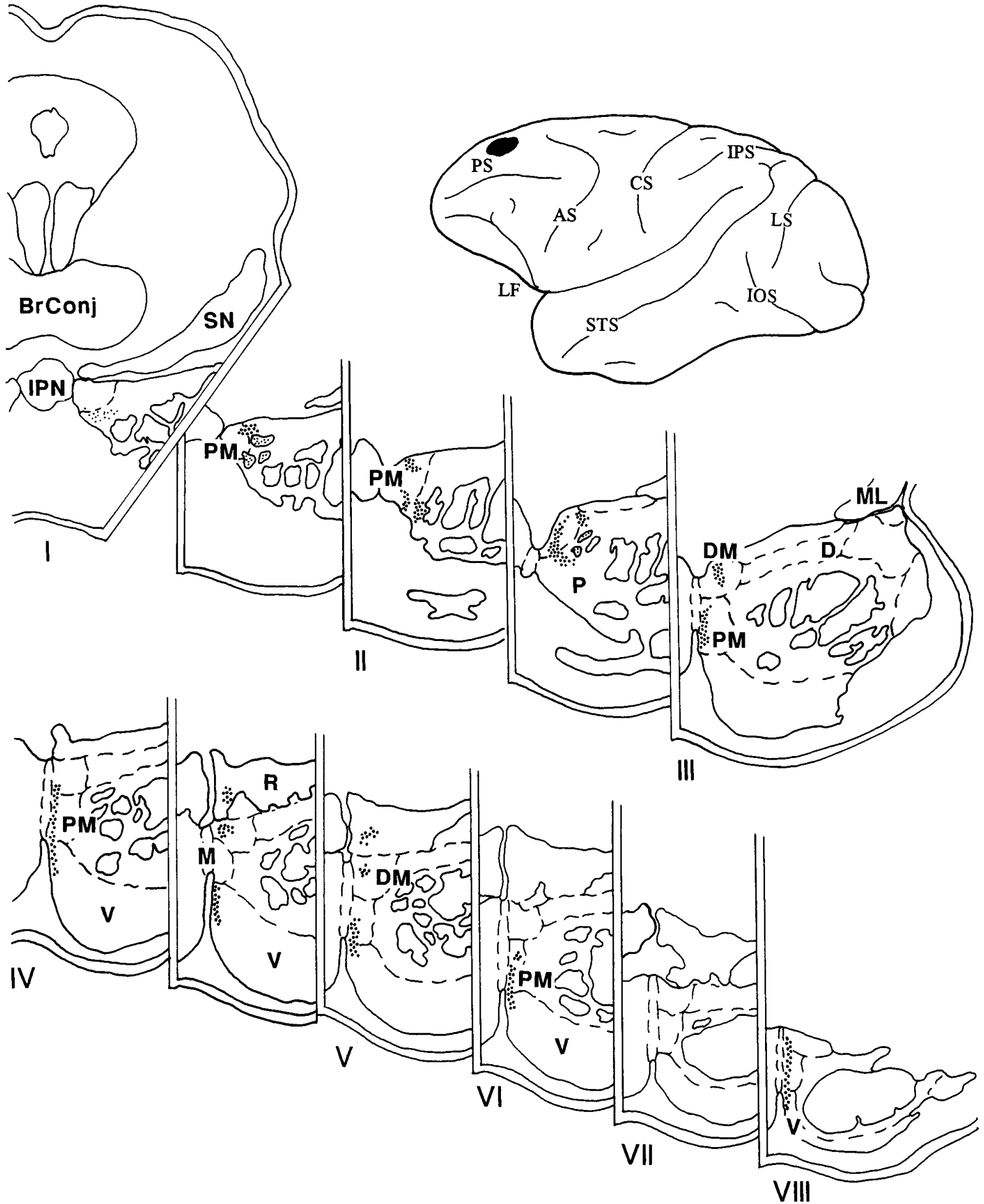

Figure 8. Diagram illustrating the lateral surface of the cerebral hemisphere of case 6, in which the isotope was injected into the PFC above the midportion of the principal sulcus and involved lateral area 9. The resulting label throughout the rostrocaudal extent of the ipsilateral pons occupied a thin dorsal-ventral lamella adjacent to the midline, spanning the paramedian nucleus and the medial part of the peripeduncular nucleus as well as the dorsomedial and ventral nuclei and the NRTP.

observed after isotope injection in area 46 below the principal sulcus or the orbitofrontal cortices including areas $11,47 / 12$, and 14 (see Fig. 16).
The general organization of the prefrontopontine projections is in agreement with the pattern observed in previous corticopontine studies (Levin, 1936; Sunderland, 1940; Nyby and Jansen, 1951; 


\section{CASE 8}

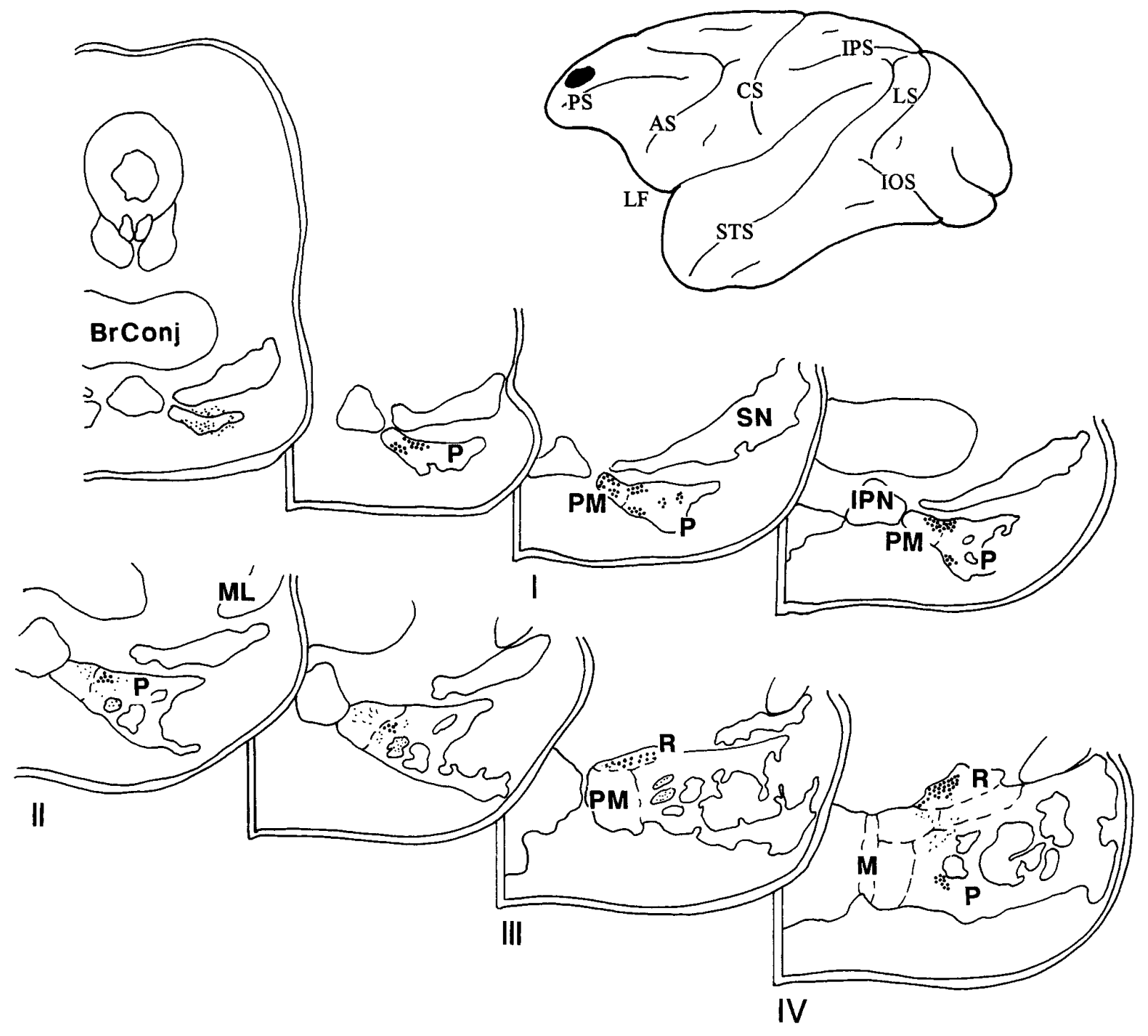

Figure 9. Diagram illustrating the lateral surface of the cerebral hemisphere of case 8 , in which isotope was placed in the rostral part of the dorsolateral PFC and involved the rostral part of area 9 and dorsal area 10. Label was restricted to the rostral half of the ipsilateral pons and was located primarily in the paramedian and peripeduncular nuclei, with some grain also in the NRTP.

Brodal, 1978, 1980; Künzle, 1978; Wiesendanger et al., 1979; Glickstein et al., 1980; Hartmann-von Monakow et al., 1981; May and Andersen, 1986; Tusa and Ungerleider, 1988; Schmahmann and Pandya, 1989, 1991, 1993). Each cortical region has termination fields scattered through the pons in patches that may be discontinuous at a given transverse pontine level or that may form part of a curvilinear patch resembling the layer of an onion. Many of these apparently discontinuous patches can be traced from one level to the next. The pontine terminations were strictly ipsilateral in this study, with the exception of terminations in the median nucleus, which borders each side of the basilar pons, and the NRTP, which has a small contralateral termination in some instances (for example, in case 3).

All areas within the PFC project to the paramedian nucleus and the adjacent medial part of the peripeduncular nucleus. The termination patterns vary, however, according to the exact site of origin both with respect to the rostrocaudal extent of the projec- tion as well as to the distribution within a given pontine level. Details of these pontine terminations are presented in Figure 16. When the terminations in each case are plotted on to a standard view of the pons (Fig. 17), it is apparent that there is little or no overlap. Whereas the same pontine nucleus may receive input from multiple cortical sites, the precise location of the projections is different for each cortical injection.

Therefore, it would appear from our observations that the PFC pontine projections have certain central defining features as follows: (1) The prefrontal projections are derived from the dorsolateral, dorsomedial, and frontopolar PFC regions, but not from the orbitofrontal and adjacent ventrolateral cortices. (2) There is a consistent projection on the paramedian pontine nucleus and the medial part of the peripeduncular nucleus. (3) There is a variable degree of projection on the dorsomedial, median, ventral, and lateral nuclei and the NRTP. (4) There are no prefrontal projections to the dorsal, dorsolateral, and extreme dorsolateral 


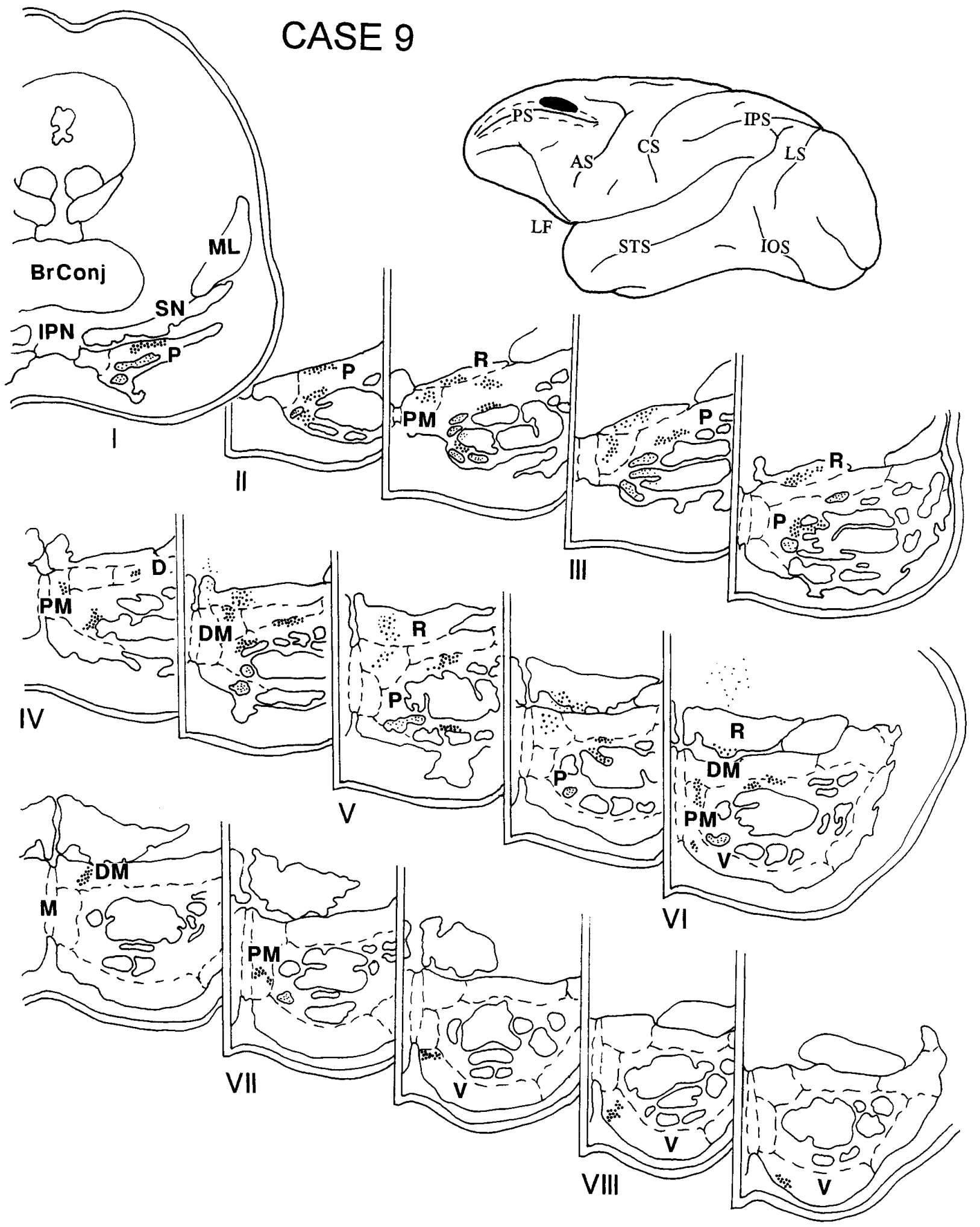

Figure 10. Diagram illustrating the lateral surface of the cerebral hemisphere of case 9, in which isotope was placed in the caudal part of the upper bank of the principal sulcus and the adjacent gyral cortex and involved area 9/46d (Fig. 9). The label was distributed throughout the rostrocaudal extent of the ipsilateral pons and was present in the peripeduncular, paramedian, and dorsomedial nuclei as well as in the NRTP and the medial part of the ventral nucleus.

pontine nuclei, and there is relative sparing of the intrapeduncular pontine nucleus. It should be noted, however, that projections to a region within the dorsolateral pons have been reported to arise from the frontal eye field located more caudally within the arcuate concavity (Astruc, 1971; Künzle and Akert, 1977; Stanton et al., 1988; Shook et al., 1990). In our study, only the rostral, sulcal part 

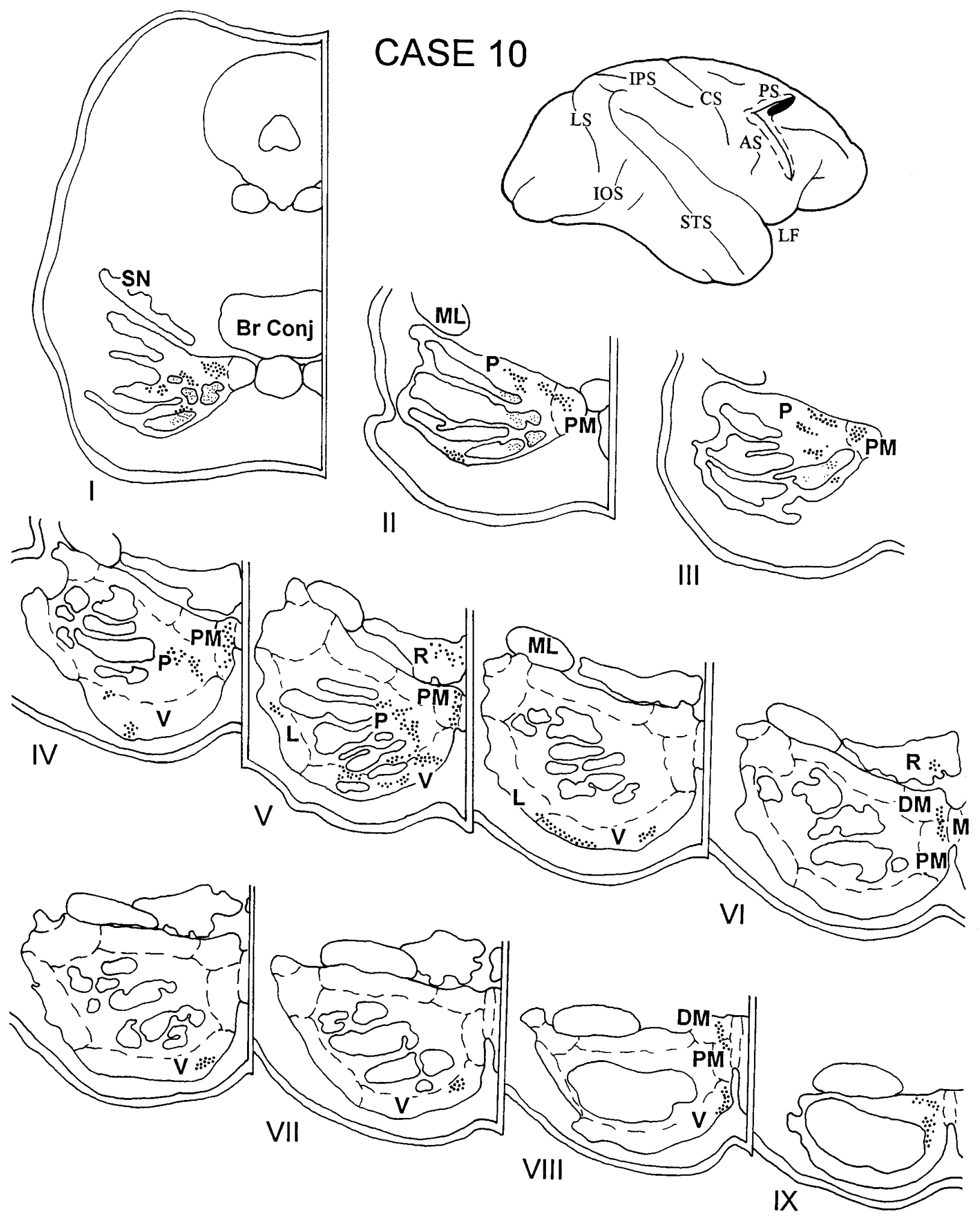

Figure 11. Diagram illustrating the lateral surface of the cerebral hemisphere of case 10, in which the isotope injection was placed in the cortex lying in the rostral bank of the upper limb of the arcuate sulcus and adjacent gyral cortex and involved area 8Ad. Terminal label was present throughout the rostrocaudal extent of the ipsilateral pons, involving primarily the paramedian and dorsomedial nuclei and the medial and ventral parts of the peripeduncular nucleus. In the caudal pons, grains were noted in the ventral and lateral nuclei, with some in the NRTP.

of area 8 was studied, because the pontine projections from these other areas have already been established. (5) It appears that the prefrontopontine pathways are further refined for each architec- tonic area by the differential rostro-caudal extent of each projection and by variations in pontine nuclear connectivity at each transverse level. 


\section{CASE 11}

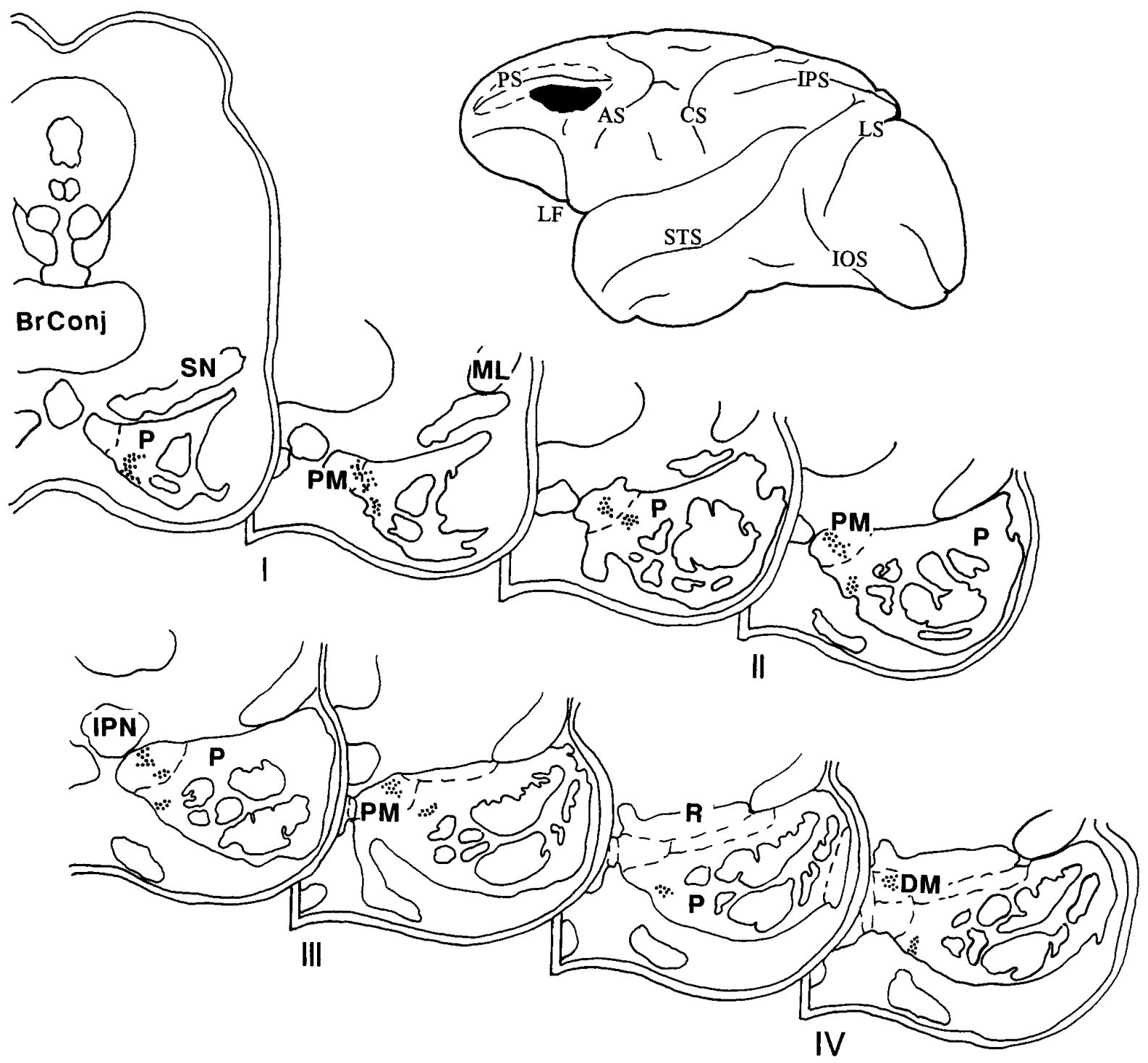

Figure 12. Diagram illustrating the lateral surface of the cerebral hemisphere of case 11, in which isotope was injected into the caudal part of the ventral bank of the principal sulcus and the adjacent gyral cortex, and involved area 9/46v. Terminal label was present in the rostral half of the ipsilateral pons in the paramedian nucleus, with some label in the dorsomedial nucleus and the medial part of the peripeduncular nucleus.

\section{DISCUSSION}

The PFC has repeatedly been shown in both humans and nonhuman primates to be an essential component of the normal integration of higher-order behavior including attention, motivation, planning, and judgment. On the basis of behavioral studies, different functional attributes have been ascribed to orbital, medial, periprincipalis, and periarcuate prefrontal regions. This multiplicity of functional processes is matched by a connectional heterogeneity such that each of the prefrontal subdivisions has a different set of connections with cortical as well as with subcortical structures (Milner, 1964; Fuster, 1980; Barbas and Mesulam, 1985; Pandya and Yeterian, 1991; Cavada and Goldman-Rakic, 1989; Boussaoud et al., 1991; Eblen and Graybiel, 1995). The present study demonstrates that this connectional heterogeneity of the PFC exists also in the corticopontine pathway. Pontine projections are derived from the dorsolateral and medial prefrontal convexities; that is, from areas $8 \mathrm{Ad}, 8 \mathrm{~B}, 9$ (lateral and medial), $10,9 / 46 \mathrm{~d}, 9 / 46 \mathrm{v}$, and 32 . These areas are important for the spatial attributes of memory, as well as executive functions such as initiative, planning, execution, and verification of willed actions and thoughts (Luria, 1966; Eslinger and Damasio, 1985; Goldman-Rakic and Friedman, 1991; Shallice and Burgess, 1991; Petrides, 1995). In addition, projections are derived from area $45 \mathrm{~B}$, which is thought to be homologous with the language area of humans (Petrides and Pandya, 1994).

In contrast, there is a lack of pontine input from the ventrolateral and orbitofrontal cortices including areas 11, 47/12, 14, and $9 / 46 \mathrm{v}$. Our study did not specifically examine the pontine projec- 


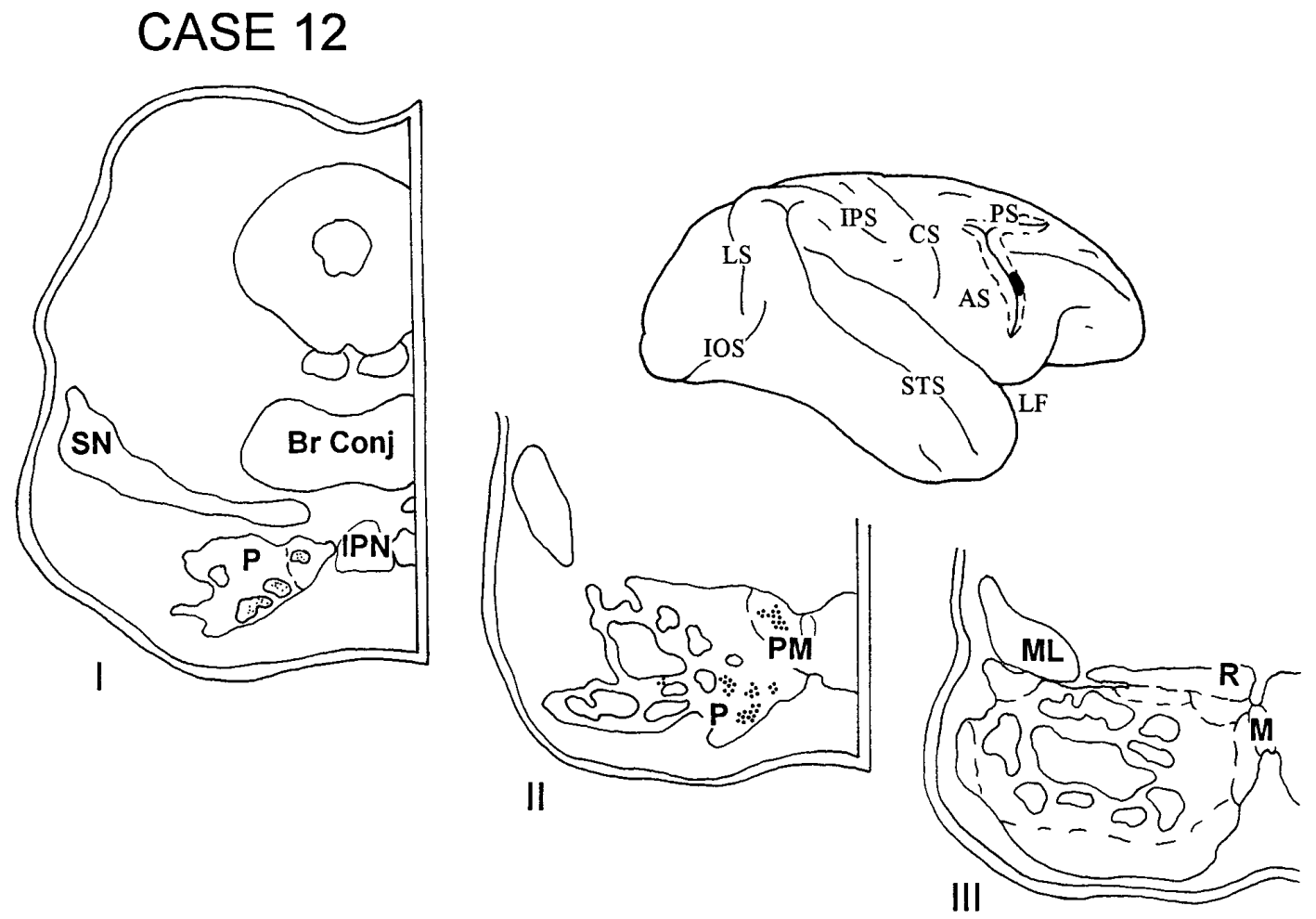

Figure 13. Diagram illustrating the lateral surface of the cerebral hemisphere of case 12, in which the isotope injection was placed in the cortex lying in the rostral bank of the lower limb of the arcuate sulcus and involved area 45B. Label was restricted to the rostral third of the ipsilateral pons and was localized in the paramedian nucleus and in the medial and ventral parts of the peripeduncular nucleus.

\section{CASE 13}

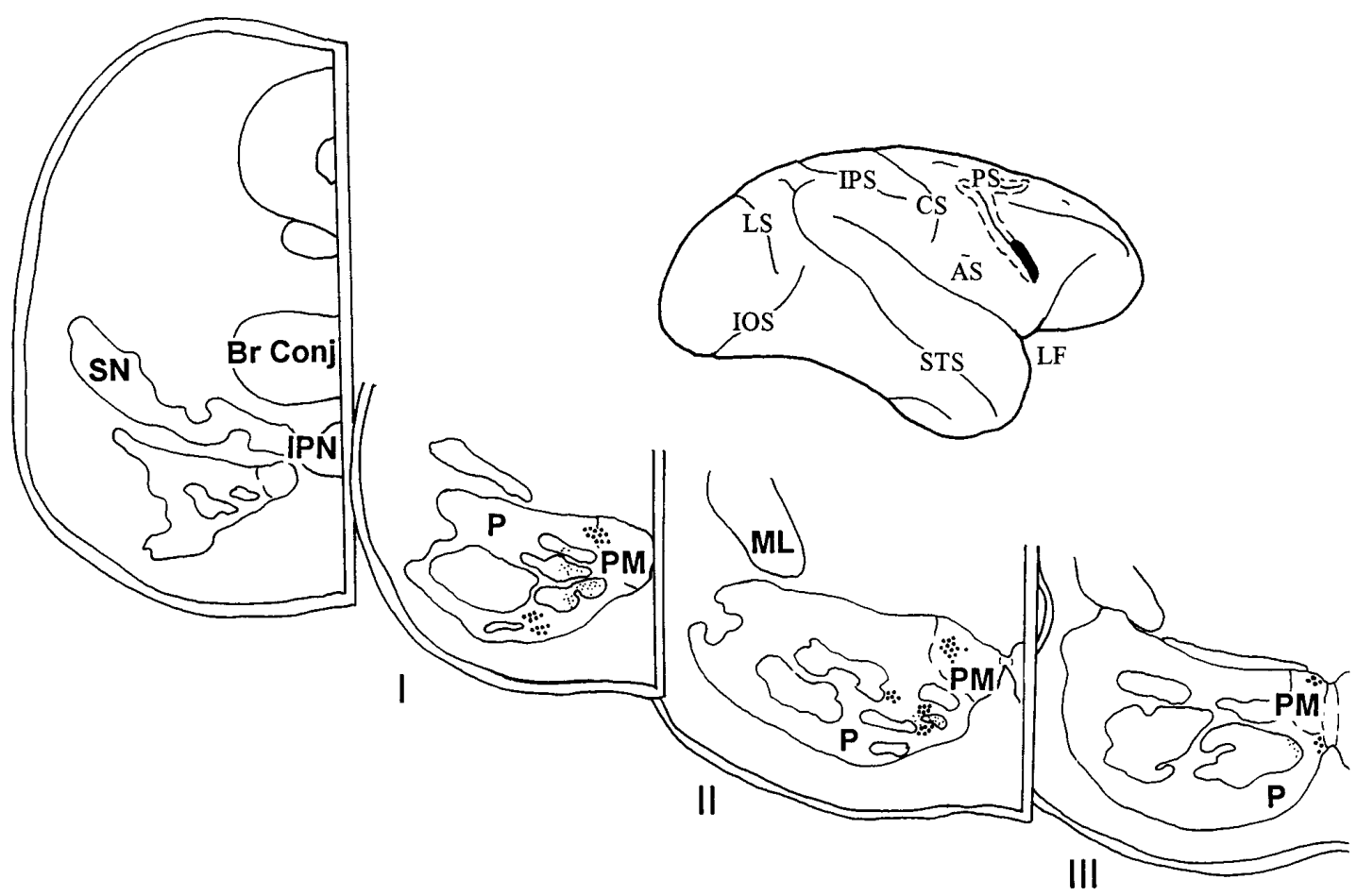

Figure 14. Diagram illustrating the lateral surface of the cerebral hemisphere of case 13, in which the injection in area $45 \mathrm{~B}$ was slightly ventral to that in the previous case. The pattern of terminations in this case was similar to case 12 and involved the paramedian nucleus and the medial and ventral parts of the peripeduncular nucleus. 

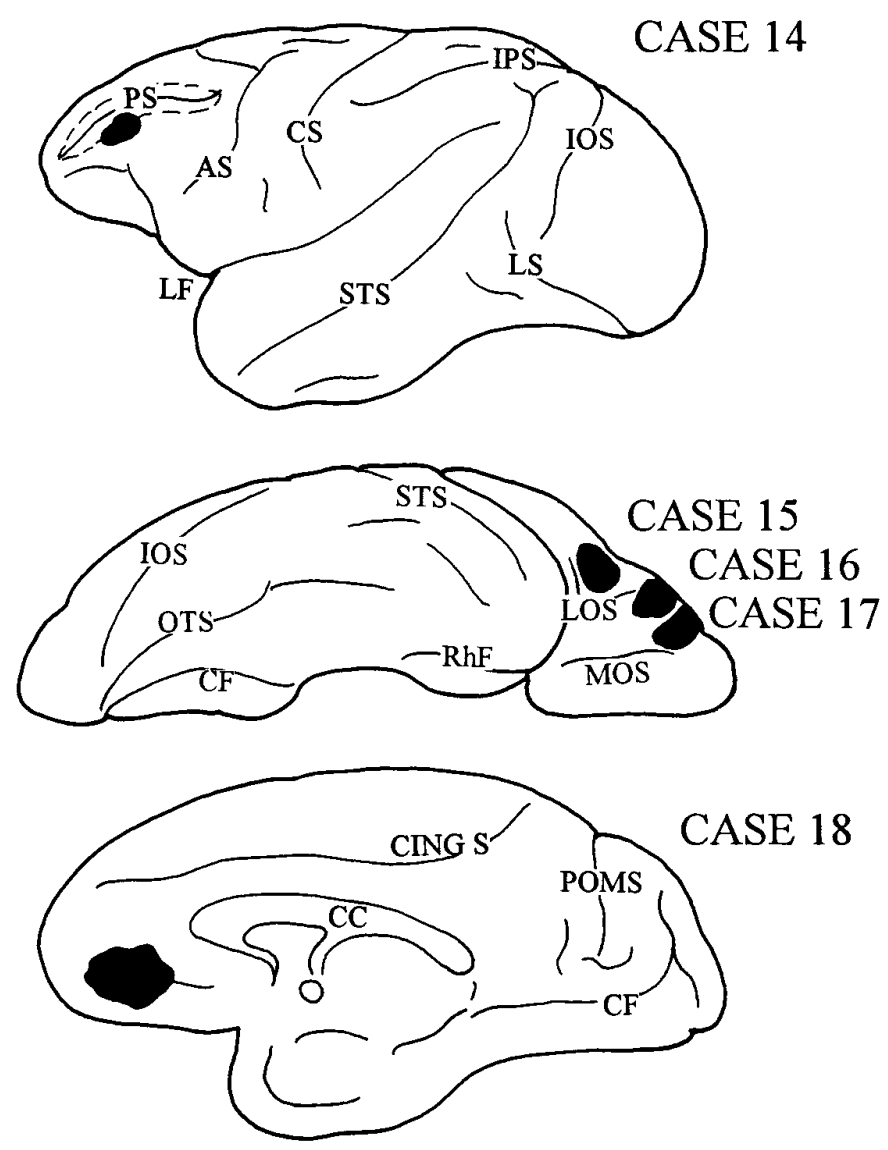

Figure 15. Diagrams illustrating the lateral, ventral, and medial surfaces of the cerebral hemispheres of a rhesus monkey, demonstrating the sites of injection that did not result in the transport of terminal label into the basilar pons. In case 14, the isotope was placed in the rostral aspect of ventral area 46; case 15 , in the caudal part of the orbital cortex in area $47 / 12$; case 16 , in the midlateral part of the orbital cortex in area $47 / 12$; case 17 , in the rostral part of the orbital cortex in area 11 ; and case 18 , in the ventral region of the medial PFC in area 14.

tions from all subdivisions of the ventral PFC, but this conclusion is supported further by reference to earlier findings (Nyby and Jansen, 1951; Brodal, 1978; Glickstein et al., 1985). These prefrontal regions have been shown to subserve object memory and recognition and aspects of autonomic and emotional response inhibition (Iversen and Mishkin, 1970; Rosvold, 1972; Bachevalier and Mishkin, 1986). This lack of pontine input from the ventrolateral and orbitofrontal cortices may at first glance be seen as problematic for the hypothesis that the cerebellum contributes to the modulation of affect and emotional states (Snider, 1950; Heath, 1977; Berman et al., 1978; Watson, 1978; Schmahmann, 1991, 1996). There is, however, a pontine projection from rostral cingulate area 32 as described here and also reported by Vilensky and Van Hoesen (1981). In addition, pontine projections are derived from the intermediate and caudal sectors of the cingulate cortex (Vilensky and Van Hoesen, 1981) and from the hypothalamus (Aas and Brodal, 1988), posterior parahippocampal gyrus (Schmahmann and Pandya, 1993), and medial mammillary bodies (Aas and Brodal, 1988). Taken together with previous demonstrations of connections between the cerebellum and the septal nuclei, hippocampus, and amygdala (Anand et al., 1959; Harper and Heath, 1973; Snider and Maiti, 1976), it is therefore apparent that the pontocerebellar system indeed receives a sizable input from limbic-related cortices.

The dichotomy in the PFC projections to the pons is reminiscent of the spatial (where) versus object (what) dichotomy (Ungerleider and Mishkin, 1982; Desimone and Ungerleider, 1989) apparent in the corticopontine projections from other association areas. Projections to pons arise from cortical areas that constitute the dorsal visual stream and that are concerned with events in the periphery of the visual field. This includes the dorsal prelunate, posterior parietal, superior temporal, and posterior parahippocampal regions, which are interconnected with the dorsolateral and dorsomedial prefrontal cortices. On the other hand, cerebral areas that form part of the ventral stream have no, or very few, pontine efferents. This includes the inferotemporal and ventral prelunate regions that have connections with the ventrolateral prefrontal region and with the orbitofrontal convexity (Brodal, 1978; Wiesendanger et al., 1979; Glickstein et al., 1980, 1985; Galletti et al., 1982; May and Anderson, 1986; Tusa and Ungerleider, 1988; Schmahmann and Pandya, 1989, 1991, 1993; Fries, 1990; Pandya and Yeterian, 1991). These anatomic connections of the feedforward limb of the cerebrocerebellar circuit were the basis of our earlier hypothesis (Schmahmann and Pandya, 1993) that the cerebellum is concerned with the visual-spatial attributes of an object including its location and direction of motion, and it is involved in the memory of those attributes. This hypothesis holds, conversely, that the cerebellum does not appear to participate in discriminative object analysis to any appreciable degree. The pattern of projections to the pons from the PFC are consistent with this hypothesis, although behavioral and physiological studies will be necessary to verify these anatomically derived conclusions.

The finding that the PFC projects to the pons conforms to the general organizing principle that interconnected cortical areas share common subcortical projections (Yeterian and Van Hoesen, 1978). These prefrontal areas are interconnected with posterior parietal, superior temporal, and parahippocampal regions (Cavada and Goldman-Rakic, 1989; Pandya and Yeterian, 1991) that themselves have pontine efferents (Nyby and Jansen, 1951; Brodal, 1978; Wiesendanger et al., 1979; Glickstein et al., 1985; May and Andersen, 1986; Tusa and Ungerleider, 1988; Schmahmann and Pandya, 1989, 1991, 1993). The converse is also true. The absence of pontine efferents from the orbitofrontal and adjacent ventrolateral cortices in this study is harmonious with findings from other studies showing that the orbitofrontal cortex is interconnected with the rostral temporal cortex, the rostral lower bank of the superior temporal sulcus, and the inferior temporal gyrus (Pandya and Yeterian, 1991), none of which have projections to the pons (Nyby and Jansen, 1951; Brodal, 1978; Glickstein et al., 1985; Schmahmann and Pandya, 1991, 1993).

The results of our investigation confirm and extend earlier reports that the paramedian and medial parts of the peripeduncular pontine nuclei seem to be the essential components in the prefrontopontine connection. This stands in contrast to the finding that posterior parietal, superior temporal, parahippocampal, and parastriate cortices have more laterally placed pontine projections, as shown previously using similar experimental methodology (Glickstein et al., 1980; Galletti et al., 1982; May and Andersen, 1986; Schmahmann and Pandya, 1989, 1991, 1993; Fries, 1990). In addition, it appears that each prefrontal cortical area has a unique complement of pontine nuclei with which it is connected. This is evident when the cases are compared with each 

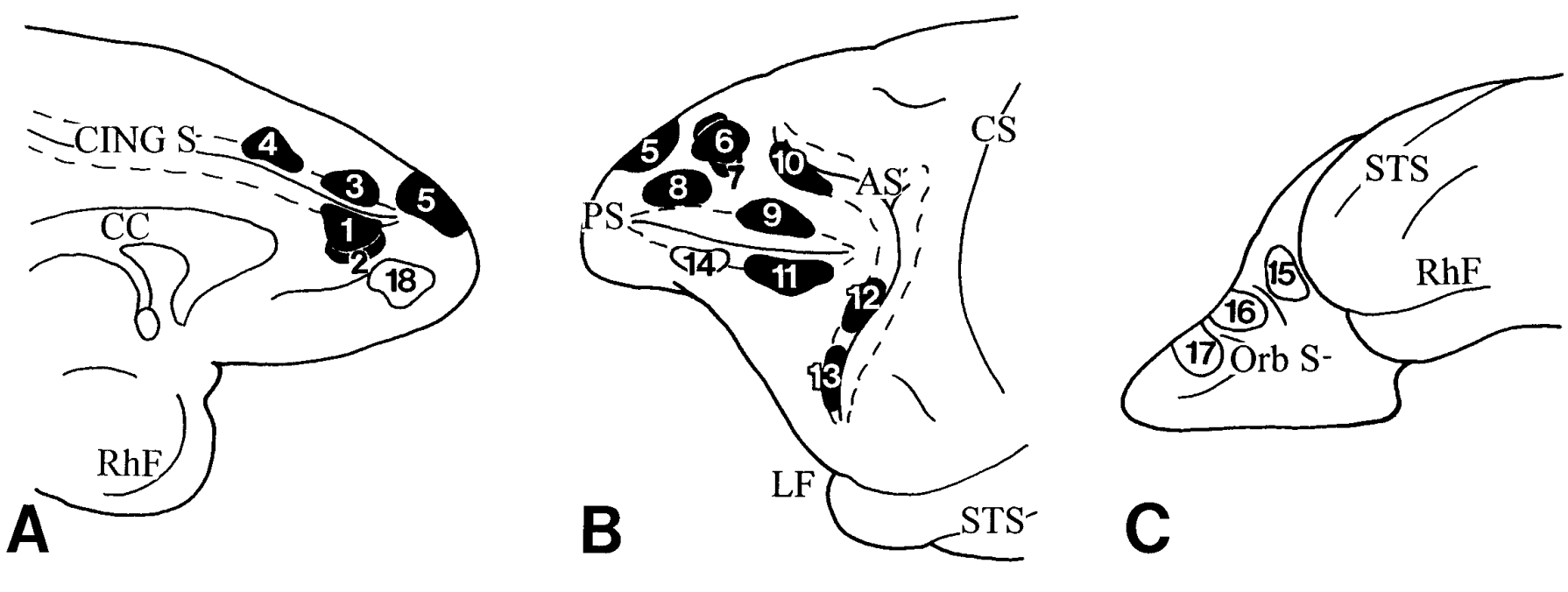

\begin{tabular}{|c|c|c|c|c|c|c|c|c|c|c|c|c|c|}
\hline $\begin{array}{c}\text { Case } \\
\text { Number }\end{array}$ & Area & $\begin{array}{c}\text { Rostro- } \\
\text { caudal } \\
\text { level }\end{array}$ & Median & Paramedian & $\begin{array}{c}\text { Peri- } \\
\text { peduncular }\end{array}$ & $\begin{array}{l}\text { Dorso- } \\
\text { medial }\end{array}$ & $\begin{array}{c}\text { Intra- } \\
\text { peduncular }\end{array}$ & Ventral & Lateral & NRTP & Dorsal & $\begin{array}{l}\text { Dorso- } \\
\text { lateral }\end{array}$ & $\begin{array}{c}\text { Extreme } \\
\text { Dorso- } \\
\text { lateral }\end{array}$ \\
\hline 1,2 & 32 & I - III & - & ++ & + & - & $=$ & - & - & - & - & - & - \\
\hline 3 & 9 (med) & I - VII & ++ & + & + & + & - & - & - & ++ & - & - & - \\
\hline 4 & $8 \mathrm{~B}$ & I-IV & - & ++ & + & - & - & - & - & + & - & - & - \\
\hline 5,8 & 10 & I - IX & - & ++4 & ++ & - & - & + & + & ++ & - & - & - \\
\hline $6,7,8$ & 9(lat) & $\mathrm{I}$ - IX & - & +++ & + & ++ & - & + & - & - & - & - & - \\
\hline 9 & $9 / 46 \mathrm{~d}$ & I - VIII & - & ++ & ++ & ++ & + & + & - & ++ & - & - & - \\
\hline 10 & $8 \mathrm{Ad}$ & $\mathrm{I}-\mathrm{IX}$ & - & +++ & ++ & + & - & + & + & + & - & - & - \\
\hline 11 & $9 / 46 \mathrm{v}$ & $\mathrm{I}-\mathrm{V}$ & - & + & + & + & - & - & - & - & - & - & - \\
\hline 12,13 & $45 \mathrm{~B}$ & I - III & - & + & + & - & - & - & - & - & - & - & - \\
\hline 14 & 46 (vent) & - & - & - & - & - & - & - & - & - & - & - & - \\
\hline 15 & $47 / 12$ & - & - & - & - & - & - & - & - & - & - & - & - \\
\hline 16 & $47 / 12$ & - & - & - & - & - & - & - & - & - & - & - & - \\
\hline 17 & 11 & - & - & - & - & - & - & - & - & - & - & - & - \\
\hline 18 & 14 & - & - & - & - & - & - & - & - & - & - & - & - \\
\hline
\end{tabular}

Figure 16. Diagrams and table illustrating the medial $(A)$, lateral $(B)$, and orbital $(C)$ surfaces of the frontal lobe of a rhesus monkey to show the sites of injection of the isotope-labeled amino acid tracer in 18 animals and the resulting distribution pattern of terminations within the nuclei of the ipsilateral basilar pons. The numbers in the injection sites correspond to the individual cases. Injections that resulted in terminations in the basilar pons are shaded in black. Those that did not result in label in the pons are unshaded. Terminations were present in different rostro-caudal levels of the pons $(I-I X)$, as well as in characteristic sets of pontine nuclei. The strength of projection in each pontine nucleus is graded absent $(-)$, mild $(+)$, moderate $(++)$, or strong $(+++)$. The injections in cases 1 and 2 were placed in area 32; case 3, in area 9 medially; case 4, in area 8B medially; case 5, in area 10 at both the medial and dorsolateral convexities; cases 6 and 7, in area 9 at the lateral convexity; case 8, in the rostral part of area 9 (lateral) and dorsal area 10; case 9, in area 9/46d; case 10, in area 8Ad; case 11, in area 9/46v; and cases 12 and 13, respectively, in the dorsal and ventral parts of area 45B. In case 14, the isotope was injected in area 46 below the principal sulcus; case 15, in area 47/12 (caudal part of the orbital cortex); case 16, in area 47/12 (midlateral portion of the orbital cortex); case 17, in area 11; and case 18, in area 14. Cortex within the walls of the cingulate sulcus, principal sulcus, and arcuate sulcus is represented by the dotted lines. 9 (med), area 9 at the medial convexity; 9(lat), area 9 at the dorsolateral convexity; 46(vent), area 46 below the principal sulcus.

other (Figs. 3-15) and as summarized in Figures 16 and 17. This finding of topographic organization within the basilar pons is reminiscent of the conclusion derived from a study of thalamic projections to the parietal lobe; namely, that each cortical area is matched by a unique constellation of neuronal groups distributed throughout a characteristic set of thalamic nuclei (Schmahmann and Pandya, 1990).

In summary, there are sizable and highly ordered inputs to the basilar pons from the prefrontal cortices. These afferents, which are then relayed to the cerebellum, are consistent with the notion that the cerebellum is an integral node in the distributed cortical-subcortical neural circuitry subserving cognitive operations. It remains to be determined, however, precisely how these prefrontopontine terminations are translated into the pontocerebellar projection. The precise topographic mapping of the associative corticopontine projections derived from the present study and from our earlier observations facilitate such future investigations. 


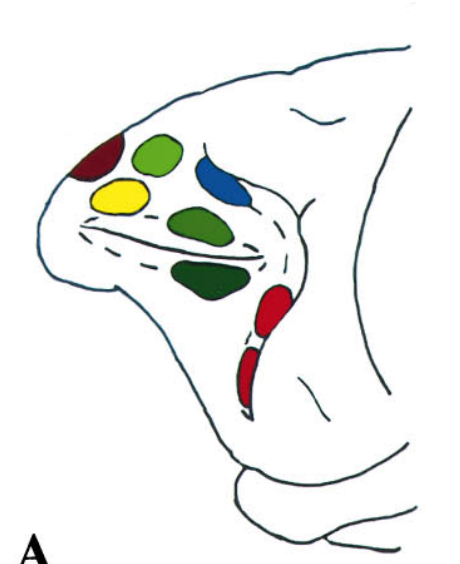

A
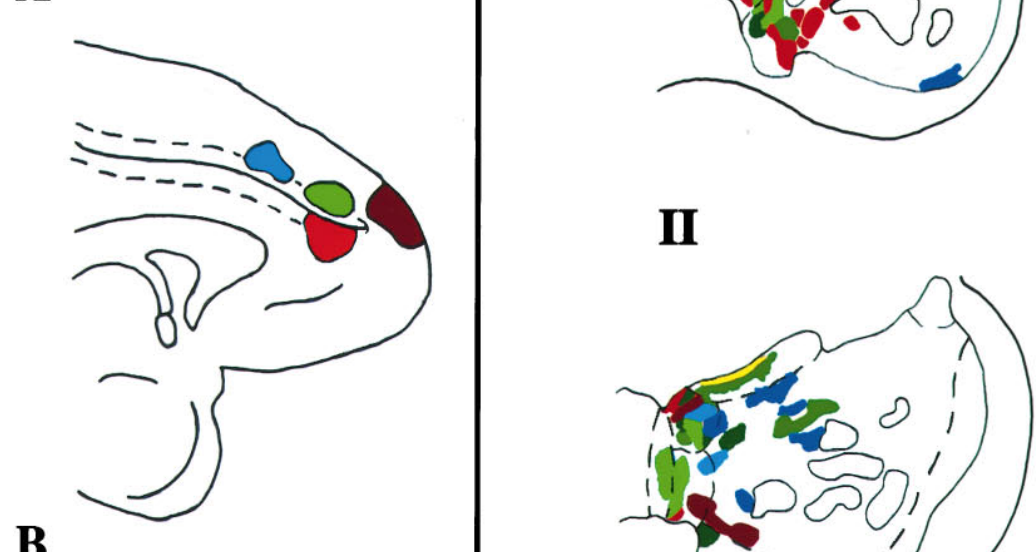

B

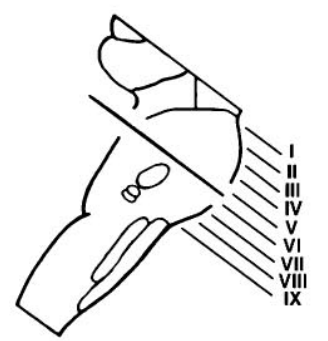

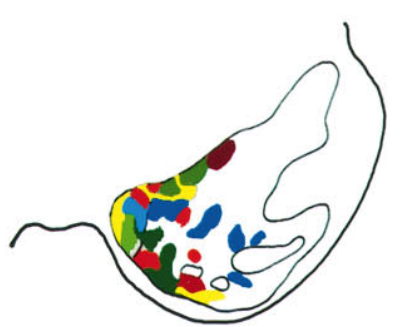

I

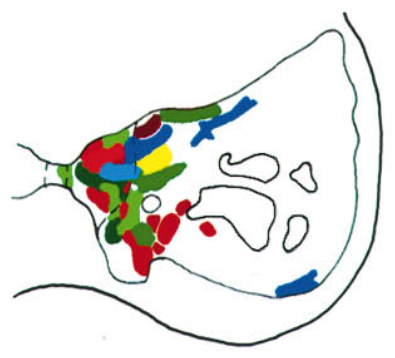

II

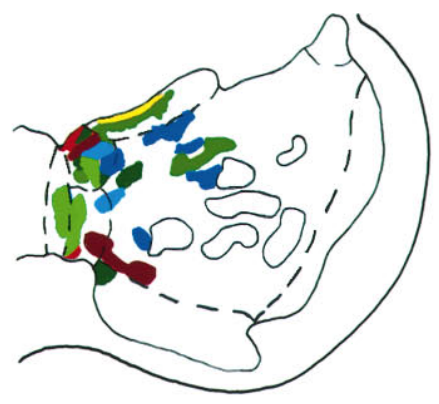

III

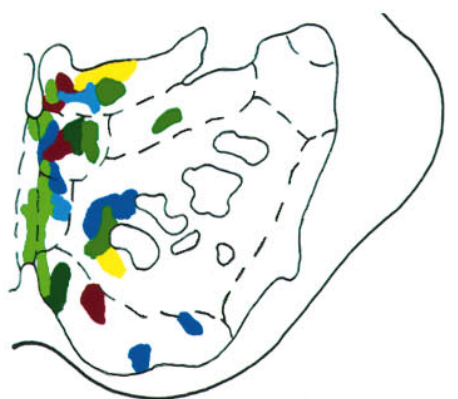

IV
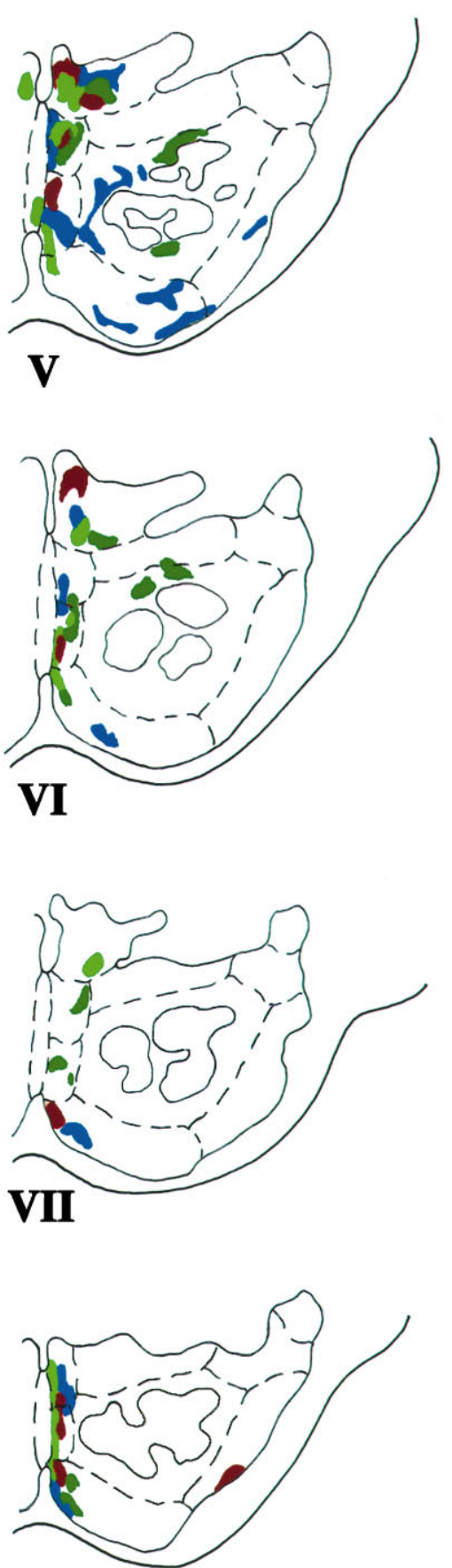

\section{VIII}

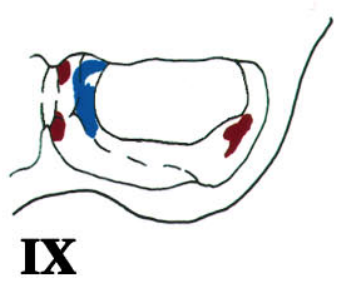

Figure 17. Composite color-coded summary diagram illustrating the distribution within the basilar pons of the rhesus monkey of projections derived from the prefrontal associative cortices. Injections in the medial $(A)$ and lateral $(B)$ surfaces of the cerebral hemisphere are shown at top left. The plane of section through the basilar pons is at bottom left. On the right, the prefrontopontine terminations for each case are shown in the rostrocaudal levels of the pons I-IX. The dashed lines in the hemisphere diagrams represent the sulcal cortices. In the pons diagrams, the dashed lines (Figure legend continues) 


\section{REFERENCES}

Aas J-E, Brodal P (1988) Demonstration of topographically organized projections from the hypothalamus to the pontine nuclei: an experimental study in the cat. J Comp Neurol 268:313-328.

Anand BK, Malhotra CL, Singh B, Dua S (1959) Cerebellar projections to the limbic system. J Neurophysiol 22:451-458.

Astruc J (1971) Corticofugal connections of area 8 (frontal eye field) in Macaca mulatta. Brain Res 33:241-256.

Bachevalier JB, Mishkin M (1986) Visual recognition impairment follows ventromedial but not dorsolateral prefrontal lesions in monkeys. Behav Brain Res 20:249-261.

Barbas H, Mesulam M-M (1985) Cortical afferent input to the principalis region of the rhesus monkey. Neuroscience 15:619-637.

Barbas H, Pandya DN (1989) Architecture and intrinsic connections of the prefrontal cortex in the rhesus monkey. J Comp Neurol 286:353-375.

Bauman ML, Kemper TL (1994) Neuroanatomic observations of the brain in autism. In: The neurobiology of autism (Bauman ML, Kemper TL, eds), pp 119-145. Baltimore: Johns Hopkins UP.

Berman AF, Berman D, Prescott JW (1978) The effect of cerebellar lesions on emotional behavior in the rhesus monkey. In: The cerebellum, epilepsy and behavior (Cooper IS, Riklan M, Snider RS, eds), pp 277-284. New York: Plenum.

Botez MI, Botez T, Elie R, Attig E (1989) Role of the cerebellum in complex human behavior. Ital J Neurol Sci 10:291-300.

Boussaoud D, Desimone R, Ungerleider LG (1991) Visual topography of area TEO in the macaque. J Comp Neurol 306:554-575.

Brodal P (1978) The corticopontine projection in the rhesus monkey. Origin and principles of organization. Brain 101:251-283.

Brodal P (1980) The cortical projection to the nucleus reticularis tegmenti pontis in the rhesus monkey. Exp Brain Res 38:19-27.

Brodmann K (1909) Vergleichende Lokalisationslehre der Grosshirnrinde in inhren Prinzipien dargestellt auf Grund des Zellenbaues. Leipzig: Barth.

Cavada C, Goldman-Rakic PS (1989) Posterior parietal cortex in rhesus monkey. I. Parcellation of areas based on distinctive limbic and sensory corticocortical connections. J Comp Neurol 287:393-421.

Cooper IS, Amin L, Gilman S, Waltz JM (1974) The effect of chronic stimulation of cerebellar cortex on epilepsy in man. In: The cerebellum, epilepsy and behavior (Cooper IS, Riklan M, Snider RS, eds), pp 119-172. New York: Plenum.

Cowan WM, Gottlieb DI, Hendrickson AE, Price JL, Woolsey TA (1972) The autoradiographic demonstration of axonal connections in the central nervous system. Brain Res 37:21-51.

Desimone R, Ungerleider LG (1989) Neural mechanisms of visual processing in monkeys. In: Handbook of neuropsychology, Vol 2 (Boller F, Grafman J, eds), pp 267-299. Amsterdam: Elsevier.

Devito JL, Smith OA (1964) Subcortical projections of the prefrontal lobe of the monkey. J Comp Neurol 123:413-419.

Dolan RJ, Bench CJ, Scott RG, Friston KJ, Frackowiak RSJ (1992) Regional cerebral blood flow abnormalities in depressed patients with cognitive impairment. J Neurol Neurosurg Psychiatry 55:768-773.

Dow RS (1974) Some novel concepts of cerebellar physiology. Mt Sinai J Med 41:103-119.

Dow RS, Moruzzi G (1958) The physiology and pathology of the cerebellum. Minneapolis: University of Minnesota.

Eblen F, Graybiel AM (1995) Highly restricted origin of prefrontal cortical inputs to striosomes in the macaque monkey. J Neurosci 15:5999-6013.

Eslinger PJ, Damasio AR (1985) Severe disturbance of higher cognition after frontal lobe ablation: patient EVR. Neurology 35:1731-1741.

Ferrier D, Turner WA (1898) An experimental research upon cerebrocortical afferent and efferent tracts. Proc Trans R Soc Lond [B] 62:1-3.

Fiez JA, Petersen SE, Cheney MK, Raichle ME (1992) Impaired nonmotor learning and error detection associated with cerebellar damage. Brain 115:155-178.
Fries W (1990) Pontine projection from striate and prestriate visual cortex in the macaque monkey: an anterograde study. Vis Neurosci 4:205-216.

Fuster JM (1980) The prefrontal cortex: anatomy, physiology and neuropsychology of the frontal lobe. New York: Raven.

Galletti C, Maioli MG, Squatrito S, Battaglini PP (1982) Corticopontine projections from the visual area of the superior temporal sulcus in the macaque monkey. Arch Ital Biol 120:411-417.

Glickstein M, Cohen JL, Dixon B, Gibson A, Hollins M, LaBossiere E, Robinson F (1980) Corticopontine visual projections in macaque monkeys. J Comp Neurol 190:209-229.

Glickstein M, May JG, Mercier BE (1985) Corticopontine projection in the macaque: the distribution of labeled cortical cells after large injections of horseradish peroxidase in the pontine nuclei. J Comp Neurol 235:343-359.

Goldman-Rakic PS (1988) Topography of cognition: parallel distributed networks in primate association cortex. Annu Rev Neurosci 11:137-156.

Goldman-Rakic PS, Friedman HR (1991) The circuitry of working memory revealed by anatomy and metabolic imaging. In: Frontal lobe function and dysfunction (Levin HS, Eisenberg HM, Benton AL, eds), pp 72-91. New York: Oxford UP.

Grafman J, Litvan I, Massaquoi S, Stewart M, Sirigu A, Hallett M (1992) Cognitive planning deficit in patients with cerebellar atrophy. Neurology 42:1493-1496.

Harper JW, Heath RG (1973) Anatomic connections of the fastigial nucleus to the rostral forebrain in the cat. Exp Neurol 39:285-292.

Hartmann-von Monakow K, Akert K, Künzle H (1981) Projection of precentral, premotor and prefrontal cortex to the basilar pontine grey and to nucleus reticularis tegmenti pontis in the monkey (Macaca fascicularis). Arch Suisse Neurol Neurochir Psychiatr 129:189-208.

Heath RG (1977) Modulation of emotion with a brain pacemaker. J Nerv Ment Dis 165:300-317.

Ito M (1993) Movement and thought. Identical control mechanisms by the cerebellum. Trends Neurosci 16:448-450.

Iversen SD, Mishkin M (1970) Perseverative interference in monkeys following selective lesions of the inferior prefrontal convexity. Exp Brain Res 11:376-386.

Jenkins IH, Brooks DJ, Nixon PD, Frackowiak RSJ, Passingham RE (1994) Motor sequence learning: a study with positron emission tomography. J Neurosci 14:3775-3790.

Kievit J, Kuypers HGJM (1977) Organization of the thalamocortical connections to the frontal lobe in the rhesus monkey. Exp Brain Res 29:299-322.

Kim SG, Ugurbil K, Strick PL (1994) Activation of a cerebellar output nucleus during cognitive processing. Science 265:949-951.

Künzle H, Akert K (1977) Efferent connections of cortical area 8 (frontal eye field) in Macaca fascicularis. A reinvestigation using the autoradiographic technique. J Comp Neurol 173:147-164.

Künzle H (1978) An autoradiographic analysis of the efferent connections from premotor and adjacent prefrontal regions (areas 6 and 9) in Macaca fascicularis. Brain Behav Evol 15:185-234.

Kuypers HGJM, Lawrence DG (1967) Cortical projections to the red nucleus and the brainstem in the rhesus monkey. Brain Res 4:151-188.

Leichnetz GR, Astruc J (1976) The efferent projections of the medial prefrontal cortex in the squirrel monkey (Saimiri sciureus). Brain Res 109:455-472.

Leichnetz GR, Smith DJ, Spencer RF (1984) Cortical projections to the paramedian and basilar pons in the monkey. J Comp Neurol 228:388-408.

Leiner HC, Leiner AL, Dow RS (1986) Does the cerebellum contribute to mental skills? Behav Neurosci 100:443-454.

Leiner HC, Leiner AL, Dow RS (1993) Cognitive and language functions of the human cerebellum. Trends Neurosci 16:444-454.

Levin PM (1936) The efferent fibers of the frontal lobe of the monkey, Macaca mulatta. J Comp Neurol 63:369-419.

\section{$\leftarrow$}

represent the pontine nuclei and the solid lines depict the traversing corticofugal fibers. It is apparent that the prefrontopontine projection is characterized by a complex mosaic of terminations in the nuclei of the basilar pons. Each cerebral cortical region has preferential sites of pontine terminations. There is considerable interdigitation of the terminations from some of the different cortical sites, but almost no overlap. The pontine terminations described in this work were mapped manually onto a standard outline of the pons. Inherent inaccuracies in this method are readily acknowledged, largely on the basis of between-case comparison, and unavoidable inaccuracies in the attempted precise transformation of the data from an actual transverse section of the pons to an idealized version. Combined anterograde tracer experiments in the same animal would be required to confirm these conclusions. 
Luria AR (1966) Higher cortical functions in man. New York: Basic Books.

May JG, Andersen RA (1986) Different patterns of corticopontine projections from separate cortical fields within the inferior parietal lobule and dorsal prelunate gyrus of the macaque. Exp Brain Res 63:265-278.

Mesulam M-M (1981) A cortical network for directed attention and unilateral neglect. Ann Neurol 10:309-325.

Mettler FA (1935) Corticofugal fiber connections of the cortex of the Macaca mulatta. The frontal region. J Comp Neurol 61:509-542.

Mettler FA (1947) Extracortical connections of the primate frontal cerebral cortex. II. Corticofugal connections. J Comp Neurol 86:119-166.

Middleton FA, Strick PL (1994) Anatomical evidence for cerebellar and basal ganglia involvement in higher cognitive function. Science $266: 458-451$.

Milner B (1964) Some effects of frontal lobectomy in man. In: The frontal granular cortex and behavior (Warren JM, Akert K, eds), pp 313-334. New York: McGraw Hill.

Nyby O, Jansen J (1951) An experimental investigation of the corticopontine projection in Macaca mulatta. Skrifter utgitt av det Norske Vedenskapsakademie; Mat Naturv Klasse 3:1-47.

Pandya DN, Yeterian EH (1991) Prefrontal cortex in relation to other cortical areas in rhesus monkey: architecture and connections. Prog Brain Res 85:63-94.

Parsons LM, Fox PT, Downs JH, Glass T, Hirsch TB, Martin CC, Jerabek PA, Lancaster JL (1995) Use of implicit motor imagery for visual shape discrimination as revealed by PET. Nature 375:54.

Petersen SE, Fox PT, Posner MI, Mintum MA, Raichle ME (1989) Positron emission tomographic studies of the processing of single words. J Cognit Neurosci 1:153-170.

Petrides M (1995) Impairments on nonspatial self-ordered and externally ordered working memory tasks after lesions of the mid-dorsal part of the lateral frontal cortex in the monkey. J Neurosci 15:359-375.

Petrides M, Pandya DN (1994) Comparative architectonic analysis of the human and the macaque frontal cortex. In: Handbook of neuropyschology, Vol 9 (Boller F, Grafman J, eds), pp 17-57. Amsterdam: Elsevier.

Posner MI, Petersen SE, Fox PT, Raichle ME (1988) Localization of cognitive operations in the human brain. Science 240:1627-1631.

Reis DJ, Doba N, Nathan MA (1973) Predatory attack, grooming and consummatory behaviors evoked by electrical stimulation of cat cerebellar nuclei. Science 182:845-847.

Rosvold H E (1972) The frontal lobe system: cortical-subcortical interrelationships. Acta Neurobiol Exp (Warsz) 32:439-460.

Rutishauser F (1899) Experimenteller Beitrage zur Stabkranzfaserung im Frontalhirn des Affen. Monatschrifte Psychiatr Neurol 5:161-179.

Ryding E, Decety J, Sjoholm H, Sternberg G, Ingvar D (1993) Motor imagery activates the cerebellum regionally. Cognit Brain Res 1:94-99.

Sasaki K, Jinnai K, Gemba H, Hashimoto S, Mizuno N (1979) Projection of the cerebellar dentate nucleus onto the frontal association cortex in monkeys. Exp Brain Res 37:193-198.

Schmahmann JD (1991) An emerging concept: the cerebellar contribution to higher function. Arch Neurol 48:1178-1187.

Schmahmann JD (1996) From movement to thought. Anatomic substrates of the cerebellar contribution to cognitive processing. Hum Brain Mapp, in press.

Schmahmann JD, Pandya DN (1987) Posterior parietal projections to the basis pontis in rhesus monkey: possible anatomical substrate for the cerebellar modulation of complex behavior? Neurology 37[Suppl 1]:291.

Schmahmann JD, Pandya DN (1989) Anatomical investigation of projections to the basis pontis from posterior parietal association cortices in rhesus monkey. J Comp Neurol 289:53-73.

Schmahmann JD, Pandya DN (1990) Anatomical investigation of projections from thalamus to the posterior parietal association cortices in rhesus monkey. J Comp Neurol 295:299-326.
Schmahmann JD, Pandya DN (1991) Projections to the basis pontis from the superior temporal sulcus and superior temporal region in the rhesus monkey. J Comp Neurol 308:224-248.

Schmahmann JD, Pandya DN (1993) Prelunate, occipitotemporal, and parahippocampal projections to the basis pontis in rhesus monkey. J Comp Neurol 337:94-112.

Schmahmann JD, Pandya DN (1994) Trajectories of the prefrontal, premotor, and precentral corticopontine fiber systems in the rhesus monkey. Soc Neurosci Abstr 20:985.

Schmahmann JD, Pandya DN (1995) Prefrontal cortex projections to the basilar pons: implications for the cerebellar contribution to higher function. Neurosci Lett 199:1-4.

Shallice T, Burgess P (1991) Higher-order cognitive impairments and frontal lobe lesions in man. In: Frontal lobe function and dysfunction (Levin HS, Eisenberg HM, Benton AL, eds), pp 125-138. New York: Oxford UP.

Sherman J, Schmahmann JD (1995) The spectrum of neuropsychological manifestations in patients with cerebellar pathology. Hum Brain Mapp [Suppl] 1:361.

Shook L, Schlag-Rey M, Schlag J (1990) Primate supplementary eye field. I. Comparative aspects of mesencephalic and pontine connections. J Comp Neurol 301:618-642.

Silveri MC, Leggio MG, Molinari M (1994) The cerebellum contributes to linguistic production: a case of agrammatic speech following a right cerebellar lesion. Neurology 44:2047-2050.

Snider RS (1950) Recent contributions to the anatomy and physiology of the cerebellum. Arch Neurol Psychol 64:196-219.

Snider RS, Maiti A (1976) Cerebellar contribution to the Papez circuit. J Neurosci Res 2:133-146.

Stanton GB (1980) Topographical organization of ascending cerebellar projections from the dentate and interposed nuclei in Macaca mulatta: an anterograde degeneration study. J Comp Neurol 190:699-731.

Stanton GB, Goldberg ME, Bruce CJ (1988) Frontal eye field efferents in the macaque monkey. II. Topography of terminal fields in midbrain and pons. J Comp Neurol 271:493-506.

Sunderland S (1940) The projection of the cerebral cortex on the pons and cerebellum in the macaque monkey. J Anat 74:201-226.

Tusa RJ, Ungerleider LG (1988) Fiber pathways of cortical areas mediating smooth pursuit eye movements in monkeys. Ann Neurol 23:174-183.

Ungerleider LG, Mishkin M (1982) Two cortical visual systems. In: Analysis of visual behavior (Ingle DJ, Goodale MA, Mansfield RJW, eds), pp 549-586. Cambridge, MA: MIT.

Vilensky JA, Van Hoesen GW (1981) Corticopontine projections from the cingulate cortex in the rhesus monkey. Brain Res 205:391-395.

von Bonin G, Bailey P (1947) The neocortex of Macaca Mulatta. Urbana, IL: University of Illinois.

Walker AE (1940) A cytoarchitectural study of the prefrontal area of the macaque monkey. J Comp Neurol 73:59-86.

Watson PJ (1978) Nonmotor functions of the cerebellum. Psychol Bull 85:944-967.

Wiesendanger R, Wiesendanger M, Ruegg DG (1979) An anatomical investigation of the corticopontine projection in the primate (Macaca fascicularis and Saimiri sciureus). II. The projection from frontal and parietal association areas. Neuroscience 4:747-765.

Yeterian EH, Pandya DN (1991) Prefrontostriatal connections in relation to cortical architectonic organization in rhesus monkeys. J Comp Neurol 312:43-67.

Yeterian EH, Van Hoesen GW (1978) Cortico-striate projections in the rhesus monkey: the organization of certain cortico-caudate connections. Brain Res 139:43-63. 